\title{
Stock-bond Return Correlation, Bond Risk Premium Fundamentals, and Fiscal-Monetary Policy Regime
}

\author{
Erica X.N. Li, Tao Zha, Ji Zhang, and Hao Zhou
}

\section{Working Paper 2020-19 \\ October 2020}

\begin{abstract}
We incorporate regime switching between monetary and fiscal policies in a general equilibrium model to explain three stylized facts: (1) the positive stock-bond return correlation from 1971 to 2000 and the negative one after 2000, (2) the negative correlation between consumption and inflation from 1971 to 2000 and the positive one after 2000, and (3) the coexistence of positive bond risk premiums and the negative stock-bond return correlation. We show that two distinctive shocks-the technology and investment shocks-drive positive and negative stock-bond return correlations under two policy regimes, but positive bond risk premiums are driven by the same technology shock.
\end{abstract}

JEL classification: G12, G18, E52, E62

Key words: stock-bond return correlation, consumption-inflation correlation, fiscal-monetary policy regime, bond risk premium, technology shock, investment shock

https://doi.org/10.29338/wp2020-19

The authors thank Hui Chen, Eric Leeper, Yang Liu, Deborah Lucas, Pengfei Wang, and participants in seminars and conferences at Cheung Kong Graduate School of Business, Tsinghua University's People's Bank of China School of Finance, the Massachusetts Institute of Technology's Sloan Business School, the Boston Fed, the Asian Bureau of Finance and Economic Research annual conference, and the Central Bank Research Association annual meeting for helpful comments. The authors also thank Dan Waggoner for his help in programming and Eric Leeper for providing them with the data. This research is supported in part by the National Science Foundation grant number SES 1558486 through the National Bureau of Economic Research. The views expressed here are those of the authors and do not necessarily reflect those of the Federal Reserve Bank of Atlanta, the Federal Reserve System, or the National Bureau of Economic Research. Any remaining errors are the authors' responsibility.

Please address questions regarding content to Erica X.N. Li, Cheung Kong, Graduate School of Business, 1 East Chang An Avenue, Oriental Plaza, Tower, E1-Floor 10, Beijing 100082, China, xnli@ckgsb.edu.cn; Tao Zha, Federal Reserve Bank of Atlanta, 1000 Peachtree Street NE, Atlanta, GA 30309-4470 and Emory University and also NBER, zmail@tzha.net; Ji Zhang, PBC School of Finance, Tsinghua University, 43 Chengfu Road, Haidian District, Beijing 100083, China, zhangji@pbcsf.tsinghua.edu.cn; or Hao Zhou, PBC School of Finance, Tsinghua University, 43 Chengfu Road, Haidian District, Beijing, 100083, China, zhouh@pbcsf.tsinghua.edu.cn.

Federal Reserve Bank of Atlanta working papers, including revised versions, are available on the Atlanta Fed's website at www.frbatlanta.org. Click "Publications" and then "Working Papers." To receive e-mail notifications about new papers, use frbatlanta.org/forms/subscribe. 


\section{INTRODUCTION}

Empirical studies have documented the time-varying correlation between returns on the market portfolio of stocks and those on long-term (5-10 years) nominal Treasury bonds Campbell et al., 2016; Christiansen and Ranaldo, 2007; Guidolin and Timmermann, 2007; Baele et al., 2010; David and Veronesi, 2013; Gourio and Ngo, 2016). This correlation was positive before 2000 but turned negative afterwards (Panel A of Figure 1) 1] At the same time, the correlation between consumption growth and inflation also changed sign around 2000 from negative to positive (Panel B of Figure 1). In addition, the risk premiums of longterm nominal Treasury bonds remain positive before and after 2000 as shown in Section 【II.

\section{FiguRE 1. Time-varying correlations - financial market and real economy}

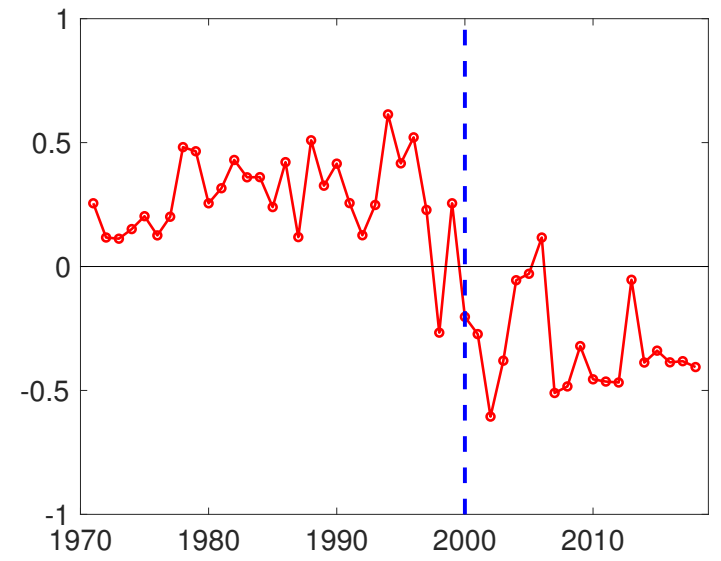

Panel A: Stock-bond return correlation

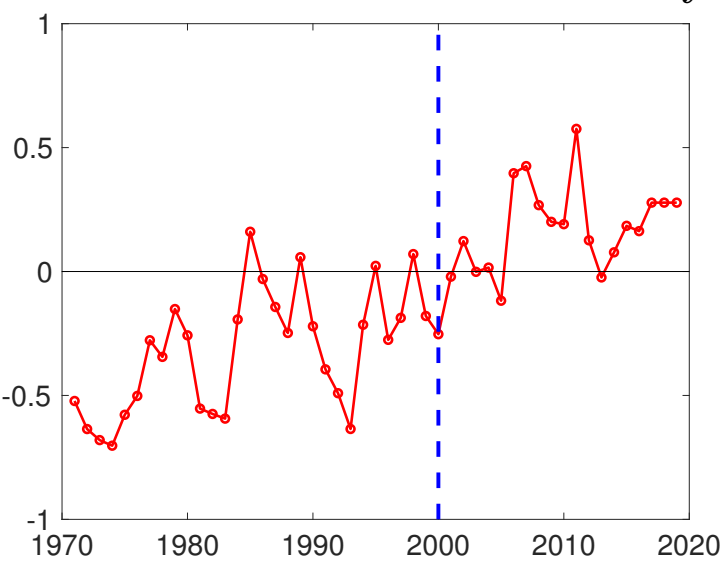

Panel B: Consumption-inflation correlation

Notes: Panel A of this figure reports the correlation between the value-weighted market return and the return on the 5-year (zero coupon) nominal Treasury bonds from 1971 to 2018 in annual frequency. The correlation is estimated based on daily returns for each year. We use the data on the 5-year zero-coupon Treasury bonds from Gürkaynak et al. (2007), which begins in 1971. Panel B displays the correlation of real consumption growth and inflation (the consumption-inflation correlation). The correlation in year $t$ is computed with the data within the 5 -year period (i.e., $[t-2, t+2]$ centering at $t$ ). Real consumption growth is based on quarterly real personal consumption expenditures per capita, and inflation is based on the quarterly GDP deflator. Both data series are obtained from the Federal Reserve Bank of St. Louis.

To account for the sign changes observed in both the financial market and the real economy, we develop a general equilibrium framework that incorporates a regime switching from the monetary regime (the $\mathrm{M}$ regime) to the fiscal regime (the $\mathrm{F}$ regime). We follow Leeper et al. (2017) and model the M regime as active monetary policy and passive fiscal policy and the

Campbell et al. (2020) run a Quandt Likelihood Ratio (QLR) test for an unknown break date based on the relationship between inflation and the output gap, the relationship between the nominal Federal Funds rate and the output gap, and the relationship between returns on stocks and long-term bonds for the sample from 1979Q3 until 2011Q4. They find that the break occurred in 2001Q2, 2000Q2, and 2000Q4, respectively. Thus, we follow Campbell et al. (2020) and choose 2000 as the break year. 
F regime as active fiscal policy and passive monetary policy. Monetary policy is modeled as a simple Taylor rule, in which the short-term nominal interest rate reacts to inflation and output gap positively. The policy rate reacts to inflation more than one-for-one under active monetary policy, while less than one-for-one under passive monetary policy. We follow Leeper (1991) and model fiscal policy as a lump-sum tax rule that reacts to government outstanding debt and output. Under passive fiscal policy, lump-sum taxes increase proportionately (in the present value) with government spending to satisfy the government budget constraint. Under active fiscal policy, the government budget constraint also holds, but taxes do not increase sufficiently to finance government spending; as a result, prices increase with government deficits to reduce the real debt burden.

Our general equilibrium framework is a new Keynesian model with four structural shocks: the technology shock defined as a shock to neutral technology (NT), the investment shock defined as a shock to the marginal efficiency of investment (MEI), the monetary policy (MP) shock, and the fiscal policy (FP) shock. In addition to technology shocks, Justiniano et al. (2010) and Kogan et al. (2017) show that MEI shocks as investment shocks, not investmentspecific technology (IST) shocks, contribute significantly to business cycle fluctuations and economic growth. Moreover, as shown in Papanikolaou (2011) and Kogan and Papanikolaou (2013), these investment shocks command significant risk premiums in financial markets. We calibrate the model to match moments of key macroeconomic and financial variables and show that technology and investment shocks, not monetary and fiscal policy shocks, are the critical structural shocks in yielding the following key results:

1. Both the positive stock-bond return correlation and the negative consumption-inflation correlation are driven by the technology shock under the $\mathrm{M}$ regime.

2. Both the negative stock-bond return correlation and the positive consumption-inflation correlation are driven by the investment shock under the $\mathrm{F}$ regime.

3. The negative stock-bond return correlation coincides with positive bond risk premiums under the $\mathrm{F}$ regime.

Since the seminal work of Sargent and Wallace (1981) and Leeper (1991), a growing literature has studied the joint behavior of monetary and fiscal authorities. We extend the standard new Keynesian model (Smets and Wouters, 2007) to incorporating this joint policy behavior as well as a recursive preference with habit formation to generate realistic risk premiums. We show that the mix of the $M$ and $F$ regimes is essential to account for the aforementioned correlation patterns and risk premiums. A positive technology shock, as a positive supply shock, causes both output and consumption to increase while driving down prices. The resulting consumption-inflation correlation becomes negative. The rise in consumption and the persistent fall in the short-term nominal interest rate as a reaction to falling inflation lead to higher stock prices and higher prices of long-term nominal Treasury 
bonds. As a result, the stock-bond return correlation is positive in response to a technology shock. Under the M regime, the interest rate falls more than inflation and thus the real interest rate falls as well. A fall in the real interest rate further stimulates output and consumption. Active monetary policy amplifies the effect of the technology shock and makes this shock a dominating force behind both the negative consumption-inflation correlation and the positive stock-bond return correlation. On the contrary, under the F regime, the nominal interest rate falls less than inflation due to passive monetary policy and as a result the real interest rate increases in response to a positive technology shock. Therefore, the stimulating effect of the technology shock is largely muted and this shock becomes unimportant for determining the correlations between consumption and inflation and between returns on stocks and on long-term bonds.

Under the F regime, the investment shock becomes the dominating force for generating the stock-bond return and consumption-inflation correlations. A positive investment shock, as a positive MEI shock, makes a transformation of investment into capital more efficient. In response to this positive demand shock, both output and investment increases but consumption decreases in the short run as an intertemporal substitution for higher consumption in the long run. The dominating effect of decreased consumption in the short-run causes stock price to fall. An increase in output leads to an increase in tax income and a decrease in the debt-to-output ratio. With active fiscal policy, taxes do not respond to a fall of the debt-to-output ratio. Thus, a combination of higher output, higher tax income, and lower debt-to-output ratio reduces government deficits. It follows from the government budget constraint that the price level must fall to make the real value of government debt more valuable. The falling price level leads to a reduction in the nominal interest rate following the Taylor rule, and as a result, bond prices go up. Hence, under the F regime, the investment shock causes negative stock-bond return correlation and positive consumption-inflation.

Consistent with the empirical observation, risk premiums of long-term Treasury bonds remain positive under the $\mathrm{F}$ regime in the model while the stock-bond correlation is negative. The key to this result is that the dynamics of the pricing kernel, thus risk premiums, in the model are driven mainly by the technology shock, regardless of the policy regime. Since stock and bond risk premiums are both positive under the technology shock, positive bond risk premium and negative stock-bond correlation coexist in the $\mathrm{F}$ regime.

Our paper belongs to a growing body of literature studying the asset pricing implications of government policies in a general equilibrium framework, which includes, in addition to the works discussed above, Andreasen (2012), Van Binsbergen et al. (2012), Rudebusch and Swanson (2012), Dew-Becker (2014), Kung (2015), Li and Palomino (2014), Bretscher, Hsu and Tamoni (2018), and Hsu, Li and Palomino (2019). The papers most closely related to our work are Song (2017), Campbell et al. (2020), and Gourio and Ngo (2016), all of which 
provide explanations for the sign change in the stock-bond return correlation. Taking the sign change of the consumption-inflation correlation around 2000 as exogenous, Song (2017) argues that an increasingly active monetary policy is the main reason for the sign change in the stock-bond return correlation. In our paper, the sign switch of the consumption-inflation correlation is endogenously determined in general equilibrium, where fiscal policy plays an indispensable role. Campbell et al. (2020) argue that the sign change in the stock-bond return correlation is driven by the changing relationship between output gap and inflation, while the latter is exogenously imposed. We focus on the economic mechanism with a mix of both active fiscal and active monetary policy that endogenously generates the time-varying correlations of both macroeconomic and financial variables. Gourio and Ngo (2016) propose a general equilibrium framework to explain the sign change in the correlation between stock returns and inflation during the zero lower bound (ZLB) period after 2008, but are silent on the bond market, which is the main focus of our paper.

The unique contribution of our paper is to model the simultaneous sign changes of the stock-bond return and consumption-inflation correlations as driven by the relative importance of technology and investment shocks under two different policy regimes. Under the $\mathrm{M}$ regime, the effect of the technology shock on these two correlations dominates that of the investment shock; while the opposite is true under the F regime, because the effect of the technology shock is largely muted by passive monetary policy. Narrative accounts of U.S. monetary-fiscal policy history as well as previous empirical studies indicate that the post-2000 period is consistent with the F regime, while the 1971-2000 period is consistent with the M regime (Davig and Leeper, 2011). By incorporating these two policy regimes in a general equilibrium framework, our model provides a coherent explanation for the changing correlation patterns in both macroeconomic and financial variables, as shown in Figure 1 .

Campbell et al. (2020)'s framework can generate the negative stock-bond correlation, but it also produces negative bond risk premiums. Unlike typical one-factor asset pricing models such as the CAPM, our model has multiple fundamental shocks and a nonlinear pricing kernel. Consistent with the empirical data, our model is capable of generating positive risk premiums in long-term bonds, even when the stock-bond return correlation is negative. We show that a switch from the $\mathrm{M}$ regime to the $\mathrm{F}$ regime is crucial in achieving the simultaneous negative stock-bond return correlation and positive bond risk premiums.

In summary, the technology shock drives negative stock-bond correlations and positive consumption-inflation correlations under the $\mathrm{F}$ regime, while the investment shock drives positive stock-bond correlations and negative consumption-inflation correlations under the M regime. These results are robust to alternative preferences - such as the CRRA and recursive preferences without habit formation - and to an expanded model with many fundamental 
shocks. Lastly, all our results hold when the nominal interest rate is at the ZLB, which is an extreme case of the $\mathrm{F}$ regime.

The rest of the paper is organized as follows. Section II discusses stylized facts and policy regimes in detail. Section III presents the general equilibrium framework with a regime switching between monetary and fiscal policies. Section IV proposes a solution method for our regime-switching model, calibrates this model to U.S. macroeconomic and financial variables, and discusses the asset pricing implications of the model. Section $\mathrm{V}$ discusses the robustness of our model outcomes. Section VI offers concluding remarks.

\section{Stylized FACTS AND POLICY REGIMES}

In this section, we discuss how to reproduce the stylized empirical facts that our theoretical model aims to explain and how to model the two policy regimes from 1971 to 2018. Appendix A provides details of the data used to reproduce these stylized facts.

II.1. Stylized facts. The key facts that motivate this paper are constructed as follows.

- The annual correlation between returns on the stock market, proxied by the stock market index, and returns on nominal (zero-coupon) Treasury bonds of 5-year maturity was 0.28 in 1971-2000 and -0.32 after 2000, as shown in Panel A of Figure 1. The annual correlations are computed using daily returns on the stock market index and on the 5-year Treasury bonds. For nominal Treasury bonds with longer maturities, the correlation statistics are very similar.

- The annual correlation between consumption growth rate and inflation was -0.32 in 1971-200 and 0.16 in the post-2000 period, as shown in Panel B Figure 1. Real consumption growth is computed with quarterly real personal consumption expenditures per capita, and inflation is the change of quarterly GDP deflator. To obtain accurate annual correlations, we calculate the consumption-inflation correlation of year $t$ using the data within the 5 -year window $[t-2, t+2]$ centered at $t$.

- Both the stock market index and nominal Treasury bonds of 5-year maturity earned positive risk premiums before and after 2000, even though the CAPM beta of the Treasury bonds, which has the same sign as the stock-bond return correlation, turned negative after 2000. Figure 2 shows that the cumulative returns on the stock market index and the Treasury bonds are both higher than that on the 1-month Treasury bills throughout the entire 1971-2018 period, indicating positive bond risk premiums both before and after 2000 .

II.2. Policy regimes. Monetary policy is modeled as

$$
r_{t}-r=\phi_{r}\left(r_{t-1}-r\right)+\left(1-\phi_{r}\right)\left[\phi_{\pi}\left(\pi_{t}-\pi^{*}\right)+\phi_{y} \Delta y_{t}\right]+\sigma_{r} e_{r, t},
$$


Figure 2. Risk premiums

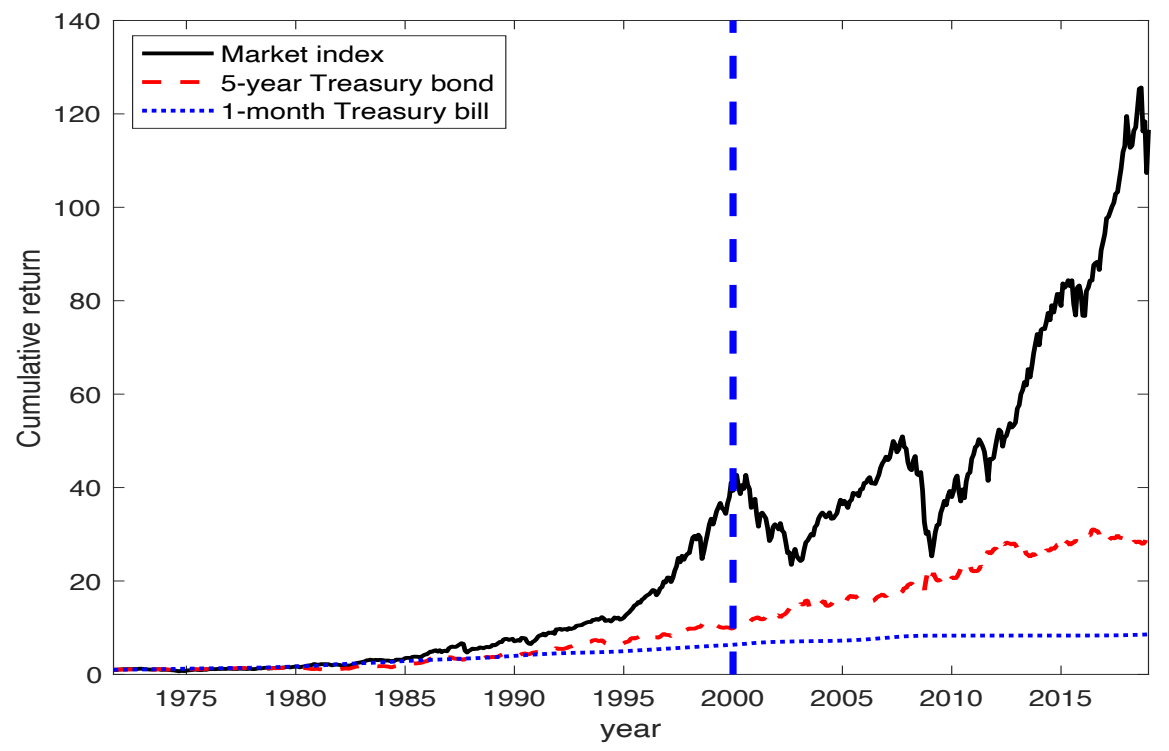

Notes: Cumulative returns on the stock market index and nominal Treasury bonds. The black solid line is the stock market index, the red dashed line represents the cumulative returns on the zero-coupon Treasury bonds with 5-year maturity, and the blue dotted line indicates the 1-month Treasury bills. Monthly returns on the stock market index and Treasury bills are obtained from Ken French's data library. Monthly returns on the 5-year Treasury bonds are computed with the daily yields provided by Gürkaynak et al. (2007).

where $r_{t}$ is the log value of the short-term nominal interest rate, and $r$ is the steady state. The policy rule has an interest-rate smoothing component captured by $\phi_{r}\left(r_{t-1}-r\right)$. The interest rate responds positively to both inflation $\pi_{t}-\pi^{*}$, where $\pi^{*}$ is the central bank's targeted inflation, and output growth $\Delta y_{t}$, where $y_{t}$ is the log value of detrended output. That is, $\phi_{\pi}(>0)$ and $\phi_{y}(>0)$. The monetary policy-MP shock is $e_{r, t} \sim \operatorname{IID} \mathcal{N}(0,1)$. If monetary policy is active, the interest rate increases more than inflation, i.e., $\phi_{\pi}>1$; if monetary policy is passive, $\phi_{\pi}<1$.

The fiscal authority faces the government's budget constraint that equates taxes and newly issued debt with government spending and debt payments. In the standard new Keynesian model (Davig and Leeper, 2011; Bianchi and Ilut, 2017), fiscal policy is modeled as

$$
\tau_{t}-\tau=\varsigma_{\tau}\left(\tau_{t-1}-\tau\right)+\left(1-\varsigma_{\tau}\right)\left[\varsigma_{b}\left(b_{t-1}-b\right)+\varsigma_{g}\left(g_{y t}-g_{y}\right)+\varsigma_{y}\left(y_{t}-y\right)\right]+\sigma_{\tau} e_{\tau, t},
$$

where $\tau_{t}$ is the ratio of lump-sum taxes to output, $b_{t-1}$ is the ratio of government debt in the previous period to output, $g_{y t}$ is the ratio of government expenditures to output, $y$ is the steady state of output, and $e_{\tau, t} \sim \operatorname{IIDN}(0,1)$ is the fiscal policy-FP shock. The coefficients $\varsigma_{\tau}, \varsigma_{b}, \varsigma_{g}$, and $\varsigma_{y}$ represent, respectively, the persistence of tax policy and the sensitivities of tax policy to government debt, government spending, and output gap. If fiscal policy is passive, taxes respond strongly to government debt with $\varsigma_{b}>\beta^{-1}-1$, where $\beta$ is the household's subjective discount factor. If taxes do not respond or respond negatively to 
outstanding government debt $\left(\varsigma_{b} \leq \beta^{-1}-1\right)$, fiscal policy is active. In this case, the price level must adjust so that the government budget constraint is satisfied. For example, prices would need to rise to reduce real government liabilities when the government's income (taxes plus new debt issuances) are insufficient to cover its spending and liabilities. Therefore, passive fiscal policy does not influence macroeconomic fluctuations except for through the level of outstanding government debt, while active fiscal policy influences the price level, which in turn affects other macroeconomic variables.

Immediately after the World War II, the Federal Reserve adopted policy to support high bond prices without responding to inflation - an extreme form of passive monetary policy (Woodford, 2001) — until the Treasury Accord of March 1951. Through the Korean War (June 1950 - July 1953), monetary policy accommodated fiscal policy by financing government debt (Ohanian, 1997). From mid 1950s through the Kennedy tax cut of 1964 into the second half of the $1960 \mathrm{~s}$, fiscal policy was active, paying little attention to the government debt. Another prolonged period of active fiscal policy began with President Bush's tax cuts in 2002 and 2003, followed by drastically increased government spending and tax cuts enabled by the Economic Stimulus Act of 2008 and the American Recovery and Reinvestment Act of early 2009 around global financial crisis. Because the yield data on long-term Treasury bonds are fragmentary prior to 1971, we focus on the changes in macroeconomic and financial dynamics around 2000, when a mix of monetary and fiscal policies switched regime.

Following Leeper et al. (2017), we term a mix of active monetary policy and passive fiscal policy "the M regime" and a mix of active fiscal policy and passive monetary policy "the F regime." According to Sims and Zha (2006) and Davig and Leeper (2011), monetary policy remained largely active after 1971 until 2000. When allowing fiscal policy to switch regime, Davig and Leeper (2011) show that monetary policy became passive after 2000 to combat the 2000 and 2007 recessions with active fiscal policy. These empirical results are consistent with the narrative account of U.S. economic policy history. In the next section, we incorporate regime switching between monetary and fiscal policies in a dynamic stochastic general equilibrium (DGSE) model and discuss the model's asset pricing implications.

\section{MODEL}

Our model follows Smets and Wouters (2007), Leeper (1991), and Bianchi and Ilut (2017). We focus on four structural shocks that are most commonly used in the macro-finance literature: the technology shock, the investment shock, the MP shock, and the FP shock.

III.1. Households. The lifetime utility function for the representative household is given by

$$
V_{t} \equiv \max _{\left\{C_{t}, L_{t}, B_{t} / P_{t}, B_{t}^{S} / P_{t}, I_{t}\right\}}\left(1-\beta_{t}\right) U\left(C_{h, t}, L_{t}\right)+\beta_{t} \mathbb{E}_{t}\left[V_{t+1}^{\frac{1-\gamma}{1-\psi}}\right]^{\frac{1-\psi}{1-\gamma}}
$$


with

$$
U_{t} \equiv U\left(C_{h, t}, L_{t}\right)=\frac{C_{h, t}^{1-\psi}}{1-\psi}-A_{t}^{L} \int_{0}^{1} \frac{L_{j, t}^{1+\phi}}{1+\phi} d j,
$$

where $\psi$ is the elasticity of intertemporal substitution, and $\phi$ is the inverse of the Frisch elasticity of labor supply. Habit-adjusted consumption $C_{h, t}$ is defined as $C_{h, t}=C_{t}-b_{h} \bar{C}_{t-1}$, where $C_{t}$ is the household's consumption, $\bar{C}_{t}$ is aggregate consumption, and $b_{h}$ is the habit parameter ${ }^{2}$ The disutility of labor, $A_{t}^{L}=a^{L}\left(z_{t}^{+}\right)^{1-\psi}$, grows at a rate of $\left(z_{t}^{+}\right)^{1-\psi}$, where $a^{L}$ is the disutility parameter and $z_{t}^{+}$is the growth rate of the economy. The supply of type $j$ labor is denoted by $L_{j, t}$.

The household maximizes its utility subject to the budget constraint

$$
\begin{aligned}
& P_{t} C_{t}+P_{b, t} B_{t}+B_{t}^{S}+\frac{P_{t}}{\Psi_{t}} I_{t}+\frac{P_{t}}{\Psi_{t}} a\left(u_{t}\right) \bar{K}_{t-1} \\
\leq & B_{t-1}\left(P_{b, t} \rho+1\right)+\left(1+r_{t-1}\right) B_{t-1}^{S}+P_{t} r_{t}^{k} u_{t} \bar{K}_{t-1}+P_{t} L I_{t}+P_{t} D_{t}-P_{t} T_{t},
\end{aligned}
$$

where $P_{t}$ is the price of consumption goods, $I_{t}$ investment measured in the unit of investment goods rather than consumption goods, and $\Psi_{t}$ the relative price of consumption to investment goods, and $\bar{K}_{t}$ the raw capital stock. The real wage income $L I_{t}$ is defined as

$$
L I_{t}=\int \frac{W_{j, t}}{P_{t}} L_{j, t} d j
$$

where $W_{j, t}$ and $L_{j, t}$ are the nominal wage and supply of type- $j$ labor.

The symbol $D_{t}$ represents the real dividend paid by firms, $T_{t}$ the lump-sum tax, and $B_{t-1}^{S}$ the one-period government bond with zero net supply in period $t-1$, whose nominal return is $r_{t-1}$. To avoid numerical complication, we follow Woodford (2001) and define $B_{t}$ as the amount of long-term government bonds issued at $t$ with non-zero net supply, each of which has a stream of infinite coupon payments that begins in period $t+1$ with $\$ 1$ and decays every period at the rate of $\rho$. The price of one such long-term bond, $P_{b, t}$, is given by

$$
P_{b, t}=\mathbb{E}_{t}\left[\sum_{s=1}^{\infty} M_{t, t+s} \rho^{s-1}\right]=\mathbb{E}_{t}\left[M_{t+1}\left(1+\rho P_{b, t+1}\right)\right],
$$

where $M_{t+1}$ is the nominal stochastic discount factor or pricing kernel from period $t$ to $t+1$ and $M_{t, t+s} \equiv \prod_{i=1}^{s} M_{t+i}$.

The symbol $r_{t}^{k}$ represents the real rental rate of productive capital paid by producers, $u_{t}$ is the capital utilization rate, and the capital used in production is

$$
K_{t}=u_{t} \bar{K}_{t-1}
$$

The nominal cost of utilization per unit of raw capital is $\frac{P_{t}}{\Psi_{t}} a\left(u_{t}\right)$, where

$$
a\left(u_{t}\right)=r^{k}\left[\exp \left(\sigma_{a}\left(u_{t}-1\right)\right)-1\right] / \sigma_{a},
$$

\footnotetext{
${ }^{2}$ In equilibrium, $C_{t}=\bar{C}_{t}$. When making decisions at time $t$, however, households take $\bar{C}_{t-1}$ as given.
} 
with $\sigma_{a}>0$.

The capital accumulation follows

$$
\bar{K}_{t}=(1-\delta) \bar{K}_{t-1}+\left[1-S\left(\frac{I_{t}}{\zeta_{t}^{I} I_{t-1}}\right)\right] I_{t} .
$$

The investment adjustment cost, $S(\cdot)$, is defined as

$$
S\left(x_{t}\right)=\frac{1}{2}\left\{\exp \left[\sigma_{s}\left(x_{t}-\exp \left(\mu^{z^{+}}+\mu^{\Psi}\right)\right)\right]+\exp \left[-\sigma_{s}\left(x_{t}-\exp \left(\mu^{z^{+}}+\mu^{\Psi}\right)\right)\right]-2\right\},
$$

where $x_{t}=\frac{I_{t}}{\zeta_{t}^{I} I_{t-1}}$ and $\exp \left(\mu^{z^{+}}+\mu^{\Psi}\right)$ is the steady state growth rate of investment. The parameter $\sigma_{s}$ is chosen such that $S\left(\exp \left(\mu^{z^{+}}+\mu^{\Psi}\right)\right)=0$ and $S^{\prime}\left(\exp \left(\mu^{z^{+}}+\mu^{\Psi}\right)\right)=0$. The marginal efficiency of investment is measured by $\zeta_{t}^{I}$ and evolves as

$$
\log \left(\frac{\zeta_{t}^{I}}{\zeta^{I}}\right)=\rho_{\zeta^{I}} \log \left(\frac{\zeta_{t-1}^{I}}{\zeta^{I}}\right)+\sigma_{\zeta^{I}} e_{t}^{\zeta^{I}}, \quad \text { and } e_{t}^{\zeta^{I}} \sim \operatorname{IIDN}(0,1)
$$

where $e_{t}^{\zeta^{I}}$ denotes the marginal efficiency of investment (MEI) shock, which we term as the investment shock throughout the paper.

III.2. Final goods producers. The final goods sector is perfectly competitive. The final goods producers combine a continuum of intermediate goods, $Y_{i, t}$, indexed by $i \in[0,1]$, to produce a homogeneous final goods, $Y_{t}$, using the Dixit-Stiglitz technology:

$$
Y_{t}=\left[\int_{0}^{1} Y_{i, t}^{\frac{1}{\lambda^{p}}} d i\right]^{\lambda^{p}}, \quad \lambda^{p}>1,
$$

where $\lambda^{p}$ measures the substitutability among different intermediate goods.

III.3. Intermediate goods producers. The intermediate goods sector is monopolistically competitive. The production of intermediate goods $i$ uses both capital and labor via the homogenous production technology

$$
Y_{i, t}=\omega\left(z_{t} L_{i, t}\right)^{1-\alpha} K_{i, t}^{\alpha}-z_{t}^{+} \varphi,
$$

where $\omega$ is a total factor productivity, $z_{t}$ is a non-stationary labor-augmenting neutral technology process, $L_{i, t}$ and $K_{i, t}$ are the labor and capital services employed by firm $i, \alpha$ is the capital share of the output, and $\varphi$ is the fixed production cost. We define $z_{t}^{+}$as

$$
z_{t}^{+}=\Psi_{t}^{\frac{\alpha}{1-\alpha}} z_{t}
$$

where the relative price of consumption goods to investment goods, $\Psi_{t}$, represents the level of the investment-specific technology. We assume that $z_{t}$ evolves as

$$
\mu_{t}^{z}=\mu_{z}\left(1-\rho_{z}\right)+\rho_{z} \mu_{t-1}^{z}+\sigma_{z} e_{t}^{z}, \quad \text { and } e_{t}^{z} \sim \operatorname{IID\mathcal {N}}(0,1)
$$


where

$$
\mu_{t}^{z}=\Delta \log z_{t}
$$

and the neutral technology (NT) shock $e_{t}^{z}$ is what we refer to as the technology shock. The growth rate of investment-specific technology faces the constant $\mu^{\Psi}=\Delta \log \Psi_{t}$. Thus, the growth rate of the economy is $\mu^{z_{t}^{+}}=\Delta \log z_{t}^{+}$. The intermediate goods industry is assumed to have no entry and exit. A fixed $\operatorname{cost} \varphi$ is chosen so that intermediate goods producers earn zero profits in the steady state.

The producers take the nominal rent of capital service $P_{t} r_{t}^{k}$ and nominal wage rate $W_{t}$ as given but have the market power to set the price of their products, facing Calvo (1983)-type price stickiness, to maximize profits. With probability $\xi_{p}$, producer $i$ cannot reoptimize its price at period $t$ and must set it according to

$$
P_{i, t}=\tilde{\pi}_{p, t} P_{i, t-1}
$$

where

$$
\tilde{\pi}_{p, t}=\left(\pi^{*}\right)^{\ell}\left(\pi_{t-1}\right)^{1-\ell}
$$

is the inflation indexation, $\ell$ is the price indexation parameter, $\pi^{*}$ is the targeted (steady state) inflation rate, and $\pi_{t} \equiv P_{t} / P_{t-1}$ is the actual inflation rate. Producer $i$ sets price $P_{i, t}$ with probability $1-\xi_{p}$ to maximize its profits, i.e.,

$$
\max _{\left\{P_{i, t}\right\}} \mathbb{E}_{t} \sum_{\tau=0}^{\infty} \xi_{p}^{\tau} M_{t, t+\tau}\left[\tilde{\theta}_{p, t \oplus \tau} P_{i, t} Y_{i, t+\tau \mid t}-s_{t+\tau} P_{t+\tau} Y_{i, t+\tau \mid t}\right]
$$

subject to the demand function

$$
Y_{i, t+\tau}=Y_{t+\tau}\left(\frac{\tilde{\theta}_{p, t \oplus \tau} P_{i, t}}{P_{t+\tau}}\right)^{-\frac{\lambda^{p}}{\lambda^{p}-1}}
$$

where $\tilde{\theta}_{p, t \oplus \tau}=\left(\prod_{s=1}^{\tau} \tilde{\pi}_{p, t+s}\right)$ for $\tau \geq 1$ and equals 1 for $\tau=0$. We denote $Y_{i, t+\tau \mid t}$ as producer $i$ 's output at time $t+\tau$ if $P_{i, t}$ is reoptimized. The real marginal cost, $s_{t+\tau}$, is given by

$$
s_{t+\tau} \equiv M C_{t+\tau}=\frac{1}{z_{t+\tau}^{1-\alpha} P_{t+\tau}}\left(\frac{W_{t+\tau}}{1-\alpha}\right)^{1-\alpha}\left(\frac{r_{t+\tau}^{k}}{\alpha}\right)^{\alpha} .
$$

The value of $s_{t+\tau}$ depends on the economic condition at $t+\tau$, and does not depend on firm $i$ 's actions.

The first order condition for the profit maximization problem with respect to $P_{i, t}$ is

$$
\sum_{\tau=0}^{\infty} \xi_{p}^{\tau} M_{t, t+\tau}\left[\tilde{\theta}_{p, t \oplus \tau}^{1+\epsilon_{p}}\left(1+\epsilon_{p}\right) P_{i, t}^{\epsilon_{p}} P_{t+\tau}^{-\epsilon_{p}} Y_{t+\tau}-\epsilon_{p} s_{t+\tau} \tilde{\theta}_{p, t \oplus \tau}^{\epsilon_{p}} P_{i, t}^{\epsilon_{p}-1} P_{t+\tau}^{1-\epsilon_{p}} Y_{t+\tau}\right]=0
$$

where $\epsilon_{p}=\lambda^{p} /\left(1-\lambda^{p}\right)$. 
All firms that reoptimize prices at period $t$ set the same price: $P_{i, t}=P_{t}^{*}$. The aggregate price evolves as

$$
P_{t}^{\frac{1}{1-\lambda^{p}}}=\left(1-\xi_{p}\right)\left(P_{t}^{*}\right)^{\frac{1}{1-\lambda^{p}}}+\xi_{p}\left(\tilde{\pi}_{p, t} P_{t-1}\right)^{\frac{1}{1-\lambda^{p}}}
$$

III.4. The labor market. Labor contractors hire workers of different labor types through labor unions and produce homogenous labor service $L_{t}$ according to the production function

$$
L_{t}=\left[\int_{0}^{1} L_{j, t}^{\frac{1}{\lambda^{w}}} d j\right]^{\lambda^{w}}, \quad \lambda^{w}>1,
$$

where $\lambda^{w}$ measures the elasticity of substitution among different labor types. The intermediate goods producers employ the homogenous labor service for the production. Labor contractors are perfectly competitive, and their profit maximization leads to the demand function for labor type $j$ as

$$
L_{j, t}=L_{t}\left(\frac{W_{j, t}}{W_{t}}\right)^{\frac{\lambda^{w}}{1-\lambda^{w}}} .
$$

Labor unions face Calvo (1983)-type wage rigidities. In each period, with probability $\xi_{w}$, labor union $j$ cannot reoptimize the wage rate of labor type $j$ and sets the wage rate according to

$$
W_{j, t}=\tilde{\pi}_{w, t} e^{\tilde{\mu}_{w, t}} W_{j t-1}
$$

where

$$
\tilde{\pi}_{w, t}=\left(\pi_{t}^{*}\right)^{\ell_{w}}\left(\pi_{t-1}\right)^{1-\ell_{w}}
$$

is the inflation indexation and $\tilde{\mu}_{w, t}=\ell_{\mu} \mu_{z^{+}, t}+\left(1-\ell_{\mu}\right) \mu_{z^{+}}$is the wage growth indexation in which $\ell_{w}$ is the wage indexation on wage and $\ell_{\mu}$ is the wage indexation on output growth. With probability $1-\xi_{w}$, labor union $j$ chooses $W_{j, t}^{*}$ to maximize its profits, and all labor unions that reoptimize wages in period $t$ set the same wage as $W_{j, t}^{*}=W_{t}^{*}$.

The aggregate wage level evolves as

$$
W_{t}^{\frac{1}{1-\lambda w}}=\left(1-\xi_{w}\right)\left(W_{t}^{*}\right)^{\frac{1}{1-\lambda w}}+\xi_{w}\left(\tilde{\pi}_{w, t} e^{\tilde{\mu}_{w, t}} W_{t-1}\right)^{\frac{1}{1-\lambda w}} .
$$

III.5. Monetary and fiscal authorities. The central bank implements a Taylor (1993)type monetary policy rule specified in (II.1), the fiscal authority adjusts the tax as a share of output according to the tax policy rule specified in (II.2).

Government's intertemporal budget constraint

$$
\frac{P_{b, t} B_{t}}{P_{t}}=R_{b, t} \frac{P_{b, t-1} B_{t-1}}{P_{t}}+G_{t}-T_{t}
$$

holds at any time $t$. We rewrite the government budget constraint as

$$
b_{t}=\frac{R_{b, t} b_{t-1} Y_{t-1}}{\prod_{t} Y_{t}}+g_{y}-\tau_{t},
$$


where government spending $G_{t}$ is assumed to be a fixed fraction of output represented by $g_{y}$.

Our regime-switching model has a unique solution under the two policy regimes, the M and $\mathrm{F}$ regimes, as discussed in Section $1 \mathrm{II} .2$.

III.6. Equilibrium. In the equilibrium, all markets are clear with the aggregate resource constraint

$$
Y_{t}=C_{t}+I_{t} / \Psi_{t}+G_{t}+a\left(u_{t}\right) \bar{K}_{t-1}
$$

\section{III.7. Asset pricing implications.}

III.7.1. The stochastic pricing kernel. The household's maximization over consumption and leisure results in the stochastic pricing kernel

$$
M_{t+1} \equiv e^{m_{t+1}}=\beta\left(\frac{C_{h, t+1}}{C_{h, t}}\right)^{-\psi}\left(\frac{V_{t+1}^{1 /(1-\psi)}}{\mathbb{E}_{t}\left[V_{t+1}^{(1-\gamma) /(1-\psi)}\right]^{1 /(1-\gamma)}}\right)^{\psi-\gamma}\left(\frac{P_{t+1}}{P_{t}}\right)^{-1} .
$$

The risk-free short-term interest rate is given by $e^{-r_{t}}=\mathbb{E}_{t}\left[M_{t+1}\right]$. Appendix B shows that the log pricing kernel can be written as

$$
m_{t+1}=\theta \log \beta-\gamma \Delta c_{h, t+1}-(1-\theta) \tilde{r}_{u, t+1}-\pi_{t+1},
$$

where $\theta=\frac{1-\gamma}{1-\psi}$ and $\tilde{r}_{u, t+1}$ is related to returns on the household's wealth portfolio, the dividend of which equals consumption minus the disutility of labor in monetary terms. The pricing kernel depends not only on the current (habit-adjusted) consumption growth, but also on the long-term growth of wealth under the recursive preference.

III.7.2. Returns on stocks. The definition of stock returns follows Abel (1999), where a stock is a claim to consumption raised to the power $\lambda, C_{t}^{\lambda}$, and $\lambda>1$ is the leverage ratio. Since dividend growth in the data is more volatile than consumption growth, the leverage ratio $\lambda$ is needed to create a wedge between dividend and consumption. The stock price and nominal stock return are given by

$$
\begin{aligned}
P_{s, t} & =P_{t} C_{t}^{\lambda}+\mathbb{E}_{t}\left[M_{t+1} P_{s, t+1}\right] \\
R_{s, t+1} & =\frac{P_{s, t+1}}{P_{s, t}-P_{t} C_{t}^{\lambda}}
\end{aligned}
$$

The stock return depends positively on the current and expected future consumption growth. Under the assumption of the log normal distribution, the expected excess return can be written as

$$
\log \mathbb{E}_{t}\left[e^{r_{s, t+1}-r_{t}}\right]=-\operatorname{cov}_{t}\left(m_{t+1}, r_{s, t+1}\right),
$$

where $r_{s, t+1} \equiv \log R_{s, t+1}$. 
III.7.3. Return and yield on the long-term bond. The gross nominal return on a long-term bond, $R_{b, t}$, is given by

$$
R_{b, t}=\frac{1+\rho P_{b, t}}{P_{b, t-1}}
$$

The expected excess bond return is

$$
\log \mathbb{E}_{t}\left[e^{r_{b, t+1}-r_{t}}\right]=-\operatorname{cov}_{t}\left(m_{t+1}, r_{b, t+1}\right)
$$

where $r_{b, t+1} \equiv \log R_{b, t+1}$. The yield $\iota_{t}$ on this bond is given by $1 / P_{b, t}-(1-\rho)$ and the effective duration is $1 /\left(1-\rho /\left(1+\iota_{t}\right)\right)$. See Appendix C for the derivation.

To understand the return and yield on a long-term bond in our model, we derive an analytical expression for the risk premium of a zero-coupon, long-term bond with maturity of $n$ periods. The log return on this bond, $r_{b, t+1}^{(n)}$, can be written a $4^{3}$

$$
\log \mathbb{E}_{t}\left[e^{r_{b, t+1}^{(n)}-r_{t}}\right]=\operatorname{cov}_{t}\left[m_{t+1}, \sum_{s=1}^{n-1} r_{t+s}\right] .
$$

Intuitively, nominal bonds are risky for investors if the bond price falls when the marginal utility rises, the latter of which can be driven by lower consumption growth or/and lower returns on wealth.4 The bond price falls when the expected risk-free interest rate (up to maturity) rises. Thus, positive covariance between the marginal utility and future interest rates until maturity implies positive bond risk premium, as indicated by Equation (III.24).

\section{Results And ANALYSis}

IV.1. Solution method. The regime-switching DSGE model is solved with the method proposed by Foerster et al. (2016). We can express the linearized system in the form of

$$
\underset{n \times n}{A_{s_{t}}} x_{t}=\underset{n \times 1}{B_{s_{t}}} x_{t-1}+\underset{n \times 1}{\Psi_{s_{t}}} \underset{n \times k}{\varepsilon_{t}}+\underset{n \times 1}{\prod_{n \times s}} \eta_{s \times 1}
$$

where $x_{t}$ is a vector stacking up all the variables including endogenous and exogenous variables (forward-looking and lagged ones) in the model, $\eta_{t}$ is a vector of expectational errors, and $\varepsilon_{t}$ is a vector of fundamental IID shocks. The solution for the regime switching model takes the following form:

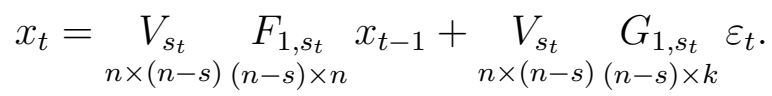

Selecting an initial starting point for the solution is the most critical and challenging task. Without a proper starting value, the solution often does not converge (Farmer et al., 2011; Bianchi and Ilut, 2017). In this paper, we propose a new procedure of randomly generating

${ }^{3}$ See $\overline{\text { Appendix D }}$ for detailed derivations.

${ }^{4}$ The dividends of the agent's wealth portfolio in our model are not consumption streams, but a combination of consumption and labor income because of the presence of leisure in the utility function. 
starting points that can lead to a speedy convergence of the solution. The procedure is based on the constant-parameter model in which the policy regime is fixed at all times. For $h$ regimes, there are $h$ constant-parameter models. For each constant-parameter model, we have the corresponding solution form

$$
x_{t}=\underset{n \times(n-s)}{V} F_{1} x_{t-1}+\underset{n \times(n) \times n}{V} \underset{(n-s)}{G_{1}} \underset{(n-s) \times k}{\varepsilon_{t}} \varepsilon_{k}
$$

with

$$
\underset{n \times n}{H_{1}}=V F_{1}, \underset{n \times k}{H_{2}}=V G_{1},
$$

where $H_{1}$ and $H_{2}$ are known matrices obtained by the method of Sims (2002) and $s$ is the dimension of sunspot shocks. Thus, the free parameters for the system have a much smaller dimension than $n^{2}$ and can be represented by $\underset{s \times(n-s)}{X}$ such that

$$
V=A^{-1}\left[\begin{array}{c}
I_{n-s} \\
-X
\end{array}\right], A^{-1}\left[\begin{array}{c}
I_{n-s} \\
-X
\end{array}\right] F_{1}=H_{1}, A^{-1}\left[\begin{array}{c}
I_{n-s} \\
-X
\end{array}\right] G_{1}=H_{2} .
$$

It follows from the above equalities that

$$
\left[\begin{array}{c}
I_{n-s} \\
-X
\end{array}\right] F_{1}=A H_{1}=\left[\begin{array}{l}
Q_{1} \\
Q_{2}
\end{array}\right] \Rightarrow F_{1}=Q_{1},-X F_{1}=-\underset{s \times(n-s)(n-s) \times n}{X} \underset{s \times n}{Q_{1}}=\underset{Q_{2},}{Q^{\prime},}
$$

which yields

$$
X=X_{q} \equiv-Q_{2} / Q_{1}
$$

Similarly,

$$
\left[\begin{array}{c}
I_{n-s} \\
-X
\end{array}\right] G_{1}=A H_{2}=\left[\begin{array}{l}
R_{1} \\
R_{2}
\end{array}\right] \Rightarrow G_{1}=R_{1},-X G_{1}=-\underset{s \times(n-s)(n-s) \times k}{X} \underset{s \times k}{R_{1}}=R_{2},
$$

which yields

$$
X=X_{r} \equiv-R_{2} / R_{1}
$$

and

$$
X=X_{q r} \equiv-\left[\begin{array}{l}
Q_{2} \\
R_{2}
\end{array}\right] /\left[\begin{array}{l}
Q_{1} \\
R_{1}
\end{array}\right] .
$$

One can use a (random) combination of $X_{q}, X_{r}$, and $X_{q r}$ as a starting point.

IV.2. Calibration. We calibrate the model to match moments of key macroeconomic and financial variables. Table A.1 lists the calibrated values of structural parameters. The steady state growth rate of the economy $\mu^{z^{+}}$is set to 0.0044 , and the steady state growth rate of the investment-specific technological change $\mu^{\Psi}$ is set to 0.0017 , implying that the average annual growth rate of the economy is $1.76 \%$. The steady state or targeted inflation rate, $\pi^{*}$, is $0.65 \%$, which means that the targeted annual inflation rate is $2.66 \%$. Government spending 
is calibrated to $18 \%$ of total output. Following the convention in the macro literature, we set the power on capital in the production function, $\alpha$, to 0.33 ; the depreciation rate on capital, $\delta$, to 0.025 ; and the wage markups, $\lambda^{w}$, to 1.05 . The long-term bond parameter $\rho$ is calibrated to 0.9627 so that the duration of the bond is 5 years. The preference parameters are taken from the long-run risk literature: the elasticity of intertemporal substitution $\psi$ is set to $1 / 1.2$, and the risk aversion parameter $\gamma$ is set to 60 so that the Sharpe ratio implied by the model (1.82) is close to that in the data (2.11). The Frisch elasticity of labor supply $\phi$ is set to 1 as in Christiano et al. (2014). We set the habit parameter $b_{h}$ to 0.85, which is within the wide range of values estimated from the literature. The objective discount factor $\beta$ is chosen to yield a $4.64 \%$ annual risk free rate.

Policy rule parameters in the two policy regimes are set according to the estimated values in Bianchi and Ilut (2017). In the M regime, monetary policy responds strongly to inflation with $\phi_{\pi}=2.7372, \phi_{y}=0.7037$, and $\phi_{r}=0.91$; fiscal policy passively adjusts to changes in government debt with $\varsigma_{b}=0.0609, \varsigma_{y}=0.3504, \varsigma_{g}=0.3677$, and $\varsigma_{\tau}=0.9844$. In the $\mathrm{F}$ regime, monetary policy is passive with $\phi_{\pi}=0.4995, \phi_{y}=0.0152$, and $\phi_{r}=0.6565$; but fiscal policy is active with $\varsigma_{b}=0, \varsigma_{y}=0.3504, \varsigma_{g}=0.3677$, and $\varsigma_{\tau}=0.8202 .^{5}$

Persistence and standard deviation parameters for the shock processes, presented in Panel D of Table A.1, are calibrated to the estimated values in Christiano, Motto and Rostagno (2014) and Justiniano, Primiceri and Tambalotti (2011), whose model structure and shock processes are very similar to ours.

We solve the model using the method discussed in Section IV.1 and generate the moments of key macroeconomic and finance variables. These moments are presented in Table 1 , along with the corresponding moments in the data. Data moments are computed with the quarterly sample from 1971Q1 - 2018Q4. Among the model moments, the computation of the equity premium and long-term bond premium are based on the covariance of the simulated stochastic discount factor $m_{t+1}$ and excess returns on equity and bond, $r_{s, t+1}-r_{t}$ and $r_{b, t+1}-r_{t}$, according to equations (III.21) and (III.23). These equations hold exactly if $m_{t+1}, r_{s, t+1}$, and $r_{b, t+1}$ follow the multivariate normal distribution.6 The transition matrix $P$ between the $\mathrm{M}$ and $\mathrm{F}$ policy regimes is set to

$$
P=\left[\begin{array}{ll}
0.98 & 0.02 \\
0.02 & 0.98
\end{array}\right],
$$

where the element $p_{i j}=\operatorname{Pr}\left(s_{t}=i \mid s_{t-1}=j\right)$ is the probability of switching from regime $j$ to regime $i$. Regime 1 corresponds to the $\mathrm{M}$ regime, and regime 2 to the $\mathrm{F}$ regime.

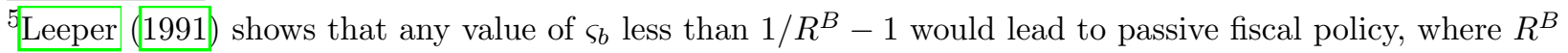
is the return on government debt. In the fiscal policy literature, however, it is standard to set $\varsigma_{b}=0$.

${ }^{6}$ We solve our model up to the first order approximation. Terms of the second and higher orders have negligible effects on the covariance. See Appendix D for a detailed analysis.
} 


\section{TABLE 1. Simulated moments}

\begin{tabular}{lccccc}
\hline \hline \multirow{2}{*}{ Variables } & \multicolumn{2}{c}{ Data } & & \multicolumn{2}{c}{ Model } \\
\cline { 2 - 3 } \cline { 5 - 6 } & Mean & Std.Dev. & & Mean & Std.Dev. \\
\hline Consumption growth $(\Delta c)$ & 1.41 & 1.78 & & 1.77 & 2.28 \\
Investment growth $(\Delta i)$ & 2.43 & 11.62 & & 2.44 & 11.31 \\
Inflation $(\pi)$ & 2.66 & 1.80 & & 2.67 & 2.28 \\
Nominal short-term interest rate $(r)$ & 4.66 & 4.42 & & 4.65 & 1.69 \\
Excess return on stock (consumption claim, $\left.r_{s}-r\right)$ & 7.99 & 16.68 & & 2.96 & 5.38 \\
Excess return on 5-year nominal bond $\left(r_{b}-r\right)$ & 2.62 & 6.18 & & 0.70 & 1.53 \\
\hline
\end{tabular}

Notes: This table reports first and second moments of key macroeconomic and financial variables. Column 1 displays the variable names. Columns 2 and 3 report the annualized mean and standard deviation (in percent) in quarterly data. Columns 4 and 5 report the corresponding simulated mean and standard deviation from the model.

As shown in Table 1, all moments of macroeconomic variables - consumption, investment, inflation, and short rate - are matched quite closely. For moments of financial variables, our model accounts for a half of the observed excess return on a nominal 5-year Treasury bond and one-third of the observed excess return on the market portfolio. This turns out to be a reasonable success for such a small scale new Keynesian model, which is intended mainly to transpire economic intuition.

IV.3. Variance decomposition. Table 2 reports variance decomposition of key macroeconomic and financial variables under the $\mathrm{M}$ and $\mathrm{F}$ regimes in our calibrated regime-switching model. Under the M regime, the variations of stock returns, nominal long-term bond returns, consumption growth, and inflation are driven mainly by the technology shock $(70.28 \%$, $75.96 \%, 63.73 \%$, and 71.95\%). Under the $\mathrm{F}$ regime, the investment shock drives a majority of variations of these variables $(71.84 \%, 92.53 \%, 57.34 \%$, and $82.14 \%)$. The technology shock, however, drives all the variations of the pricing kernel under both $\mathrm{M}$ and $\mathrm{F}$ regimesalmost $100 \%$. The effects of monetary and fiscal policy shocks are negligible in both M and F regimes. These results are crucial for understanding regime-dependent dynamics of the consumption-inflation correlation, the stock-bond return correlation, and stock and bond risk premiums.

The correlation of two variables driven by multiple fundamental shocks depends on the relative importance of each shock in contribution to the fluctuations of these variables. As Appendix E shows, the correlation of stock and bond returns $\left(r_{b}\right.$ and $\left.r_{s}\right)$ can be written as

$$
\operatorname{Corr}\left(r_{b}, r_{s}\right)=\sum_{e=1}^{n^{s}} \mathcal{S}\left(h_{b, e}\right) \mathcal{S}\left(h_{s, e}\right) \sqrt{\mathcal{V}_{b, e} \mathcal{V}_{s, e}},
$$




\section{TABLE 2. Variance decomposition (\%)}

\begin{tabular}{lcccc}
\hline \hline Variables & $\begin{array}{c}\text { Technology }\left(e_{z}\right) \\
(\mathrm{M} / \mathrm{F})\end{array}$ & $\begin{array}{c}\text { Investment }\left(e_{\zeta^{I}}\right) \\
(\mathrm{M} / \mathrm{F})\end{array}$ & $\begin{array}{c}\text { Monetary Policy }\left(e_{r}\right) \\
(\mathrm{M} / \mathrm{F})\end{array}$ & $\begin{array}{c}\text { Fiscal Policy }\left(e_{\tau}\right) \\
(\mathrm{M} / \mathrm{F})\end{array}$ \\
\hline$r_{s}-r$ & $\mathbf{7 0 . 2 8} / 26.41$ & $20.34 / \mathbf{7 1 . 8 4}$ & $9.08 / 1.58$ & $0.30 / 0.17$ \\
$r_{b}-r$ & $\mathbf{7 5 . 9 6} / 3.86$ & $2.75 / \mathbf{9 2 . 5 3}$ & $15.89 / 3.38$ & $5.40 / 0.24$ \\
$\Delta c$ & $\mathbf{6 3 . 7 3} / 41.94$ & $33.13 / \mathbf{5 7 . 3 4}$ & $3.02 / 0.63$ & $0.12 / 0.09$ \\
$\pi$ & $\mathbf{7 1 . 9 5} / 17.71$ & $24.81 / \mathbf{8 2 . 1 4}$ & $1.74 / 0.02$ & $1.51 / 0.12$ \\
$m$ & $\mathbf{9 9 . 9 5} / \mathbf{9 9 . 9 9}$ & $0.04 / 0.00$ & $0.00 / 0.00$ & $0.00 / 0.00$ \\
\hline
\end{tabular}

Notes: This table reports the one-quarter-ahead forecast error variance decomposition of the key variables in the regime switching model: excess return on stock $\left(r_{s}-r\right)$, which is a claim on consumption, excess return on 5-year nominal bond $\left(r_{b}-r\right)$, growth rate of consumption $(\Delta c)$, inflation $(\pi)$, and nominal pricing kernel $(m)$. The second to fifth columns are contributions of the technology shock, investment shock, monetary policy shock, and fiscal policy shock. The numbers before and after the slash $(/)$ represent percentage contributions of the corresponding shocks in the $\mathrm{M}$ and $\mathrm{F}$ regimes.

where $\mathcal{V}_{s, e}$ is the contribution of shock $e$ to the variance of $r_{s}, \mathcal{S}\left(h_{s, e}\right)$ equals 1 if the sign of the impulse response of $r_{s}$ to shock $e, h_{s, e}$, is positive and equals -1 otherwise, $\mathcal{V}_{s, e}$ and $\mathcal{S}\left(h_{s, e}\right)$ are defined similarly for bond return $r_{b}$, and $n^{s}$ is the number of shocks. As Equation IV.4 shows, the stock-bond return correlation is determined by a fundamental shock that contributes most to the variances of stock and bond returns (i.e., shock $e$ that has the largest values of $\mathcal{V}_{b, e} \mathcal{V}_{s, e}$ ). The same argument applies to the consumption-inflation correlation. Thus, the variance decomposition results reported in Table 2 imply that the signs of the consumption-inflation and stock-bond return correlations are dominated by the technology shock under the $\mathrm{M}$ regime and by the investment shock under the $\mathrm{F}$ regime.

The risk premiums of stock and bond depend on the covariances between the pricing kernel and the returns on stock and bond, as shown in Equation III.21 and Equation III.23. Because the pricing kernel variation is dominated by the technology shock under both regimes, the risk premiums of stock and bond are mostly determined by the technology shock as well. In the next several subsections, we discuss the dynamic responses of financial market and macroeconomic variables to the two most important structural shocks, technology and investment shocks, and show that our results are qualitatively consistent with the observed stylized facts.

IV.4. Impulse responses to the technology shock. Figure 3 presents the impulse responses of excess returns of stock and bond, the nominal interest rates, consumption growth, and inflation to a one-standard-deviation positive technology shock in the M (blue solid lines) and F (red dashed lines) regimes [7 In response to a positive technology shock, consumption rises, but inflation falls; because the technology shock is a supply shock. In response to the

$\overline{{ }^{7} \text { The impulse responses of other variables to a positive technology shock are plotted in Figure A.7. }}$ 
FIGURE 3. Impulse responses of a positive technology shock
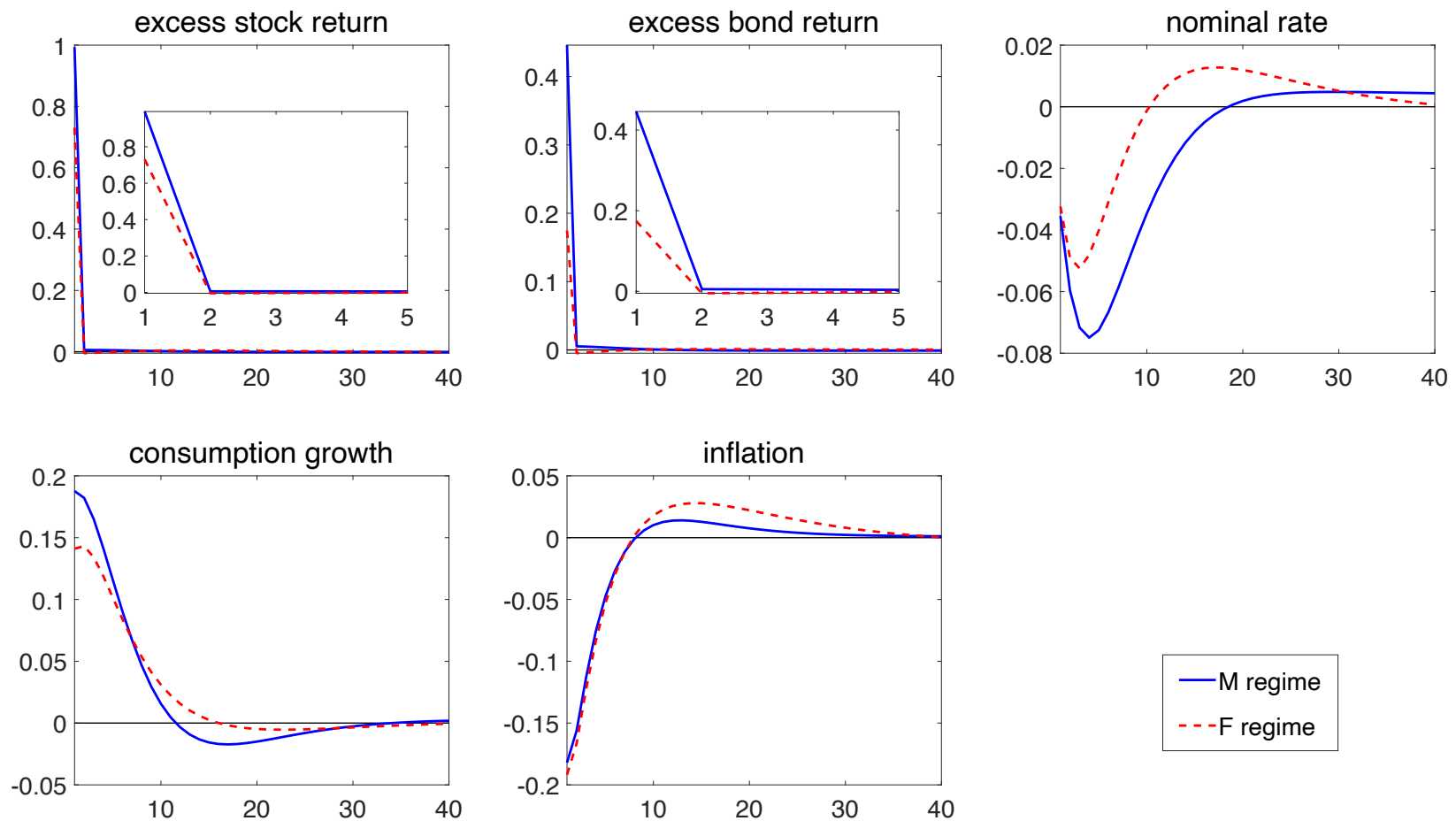

Notes: This figure plots the impulse responses of key macro and finance variables in the model after a onestandard-deviation positive technology shock. The blue solid lines and red dashed lines represent impulse responses under the $\mathrm{M}$ and $\mathrm{F}$ regimes, respectively. The $\mathrm{x}$-axis shows the time in quarters, and the $\mathrm{y}$-axis represents the percentage change from the steady state.

falling inflation, the nominal interest rate declines under the Taylor rule. Stock prices rise with rising consumption, and bond prices rise with falling nominal interest rates. Therefore, the technology shock leads to a negative consumption-inflation correlation and a positive stock-bond return correlation.

The variance decomposition in Table 2 shows that the pricing kernel is almost solely determined by the technology shock under both regimes. Because the technology shock is a persistent shock (shock on the growth rate of the technology level), both the current consumption and return on wealth go up in reaction to a positive shock, resulting in a large drop in the pricing kernel. Consequently, the risk premiums of stock and bond are positive regardless of the policy regime.

Figure 3 shows that stock and bond returns rise in larger magnitude under the M regime than under the $\mathrm{F}$ regime. The nominal interest rate is more responsive to the fall of inflation, amplifying the effects of the technology shock. Consequently, consumption rises more and so do stock prices in the $\mathrm{M}$ regime than in the $\mathrm{F}$ regime. There is a more persistent fall in the interest rate under the $\mathrm{M}$ regime. Figure 3 shows that the negative effect of the technology 
FIGURE 4. Impulse responses of a positive investment shock
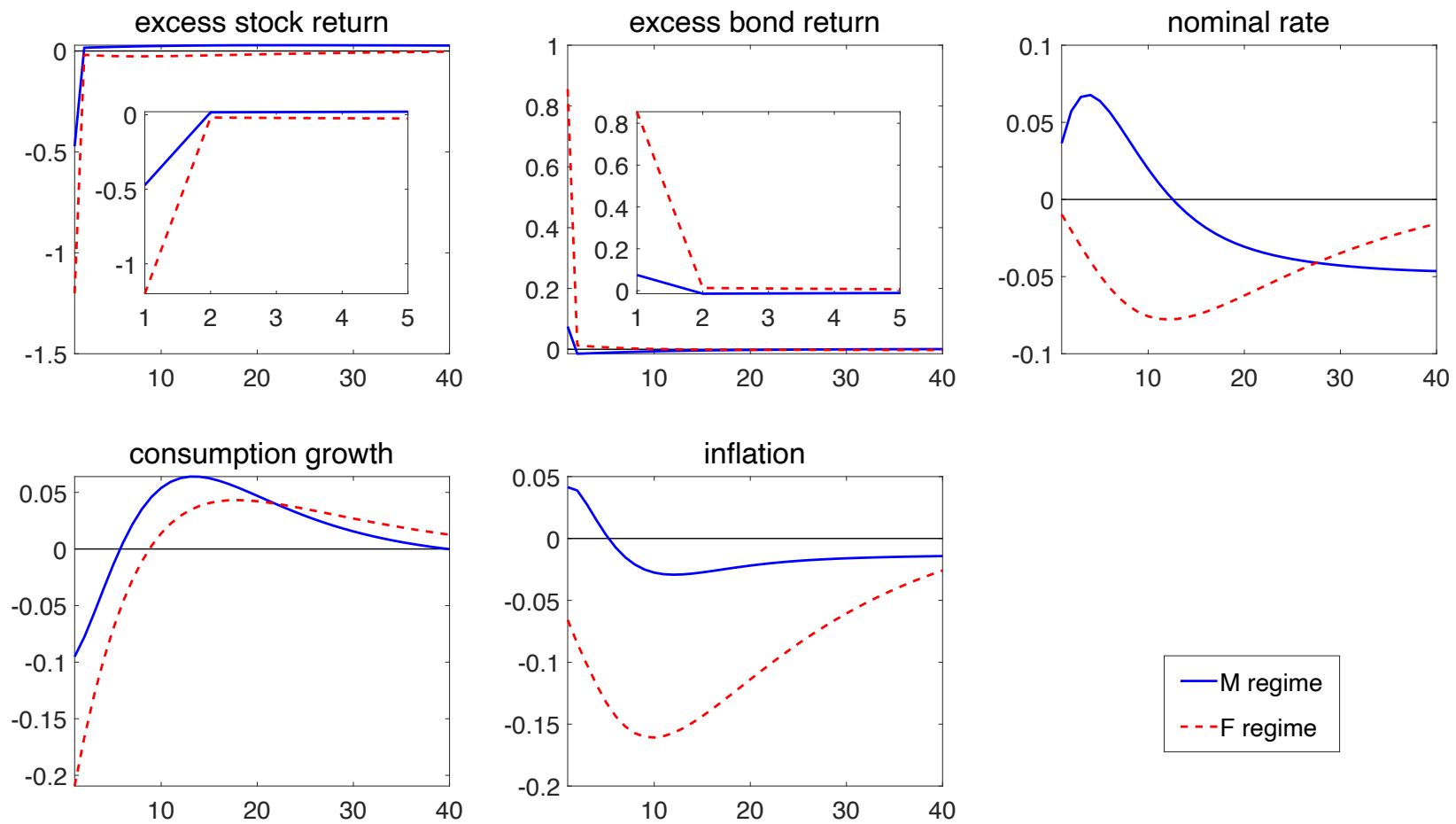

Notes: This figure plots the impulse responses of key macro and finance variables in the model after a onestandard-deviation positive investment shock. The blue solid lines and red dashed lines represent impulse responses under the $\mathrm{M}$ and $\mathrm{F}$ regimes, respectively. The $\mathrm{x}$-axis shows the time in quarters, and the $\mathrm{y}$-axis represents the percentage change from the steady state.

shock on the nominal interest rate lasts up to 20 quarters in the $\mathrm{M}$ regime, while it lasts only 10 quarters in the $\mathrm{F}$ regime.

The price of a long-term bond depends not only on the current nominal interest rate, but also on nominal interest rates in all horizons until the bond maturity. Therefore, the excess bond return in the $\mathrm{M}$ regime rises much more than it does in the $\mathrm{F}$ regime, because of the larger and more persistent fall in nominal interest rates in all horizons. These dynamic responses are consistent with the variance decomposition reported in Table 2; a much higher percentage of variations in stock and bond returns, consumption growth, and inflation are explained by the technology shock in the $\mathrm{M}$ regime than in the $\mathrm{F}$ regime.

IV.5. Impulse responses to the investment shock. Figure 4 presents the impulse responses of excess stock and bond returns, consumption growth, inflation, and the nominal interest rate to a one-standard-deviation positive investment shock in the $\mathrm{M}$ (blue solid lines) and $\mathrm{F}$ (red dashed lines) regimes $\mathrm{P}^{8}$ A positive investment shock means a more efficient transformation of investment into capital, generating higher demands for investment goods, i.e., the investment shock is a demand shock. Both output and investment increase, but

${ }^{8}$ The impulse responses of other variables to a positive investment shock are plotted in Figure A.8. 
consumption decreases in the short run, as an intertemporal substitution for higher consumption in the long run. Stock prices fall in general, due to the dominating effect of falling consumption in the short run.

In the $\mathrm{M}$ regime, general prices rise first in response to higher demands for output and then fall after about 5 quarters. With the Taylor rule, the nominal interest rate similarly rises in short horizons but then falls in horizons longer than 12 quarters. Because the price of a long-term bond depends on the interest rate in all horizons until the bond maturity, the overall effect of a positive investment shock on long-term bond prices turns out to be positive. Therefore, the investment shock generates a negative stock-bond return correlation and a negative consumption-inflation correlation in the $\mathrm{M}$ regime.

In the F regime, however, inflation falls sharply and persistently after a positive investment shock. With active fiscal policy, an increase in output leads to an increase in tax income and a decrease in the debt-to-output ratio, and taxes do not respond to the fall of the debtto-output ratio. A combination of higher output, higher tax income, and the lower debt-tooutput ratio reduces government deficits. It follows from the government budget constraint that the price level must fall to make the real value of government debt more valuable. With the Taylor rule, the nominal interest rate falls over all horizons, resulting in a large increase of the long-term bond price. Higher tax income further depresses consumption. As a result, the responses of both stock and bond returns to the investment shock are larger in the $\mathrm{F}$ regime than in the $\mathrm{M}$ regime, although the directions of these responses are the same under both regimes. The most important finding is that the consumption-inflation correlation turns positive in the $\mathrm{F}$ regime in response to the investment shock. These dynamic responses are consistent with the variance decomposition results reported in Table 2 ; the investment shock dominates the dynamics of stock and bond returns, consumption growth, and inflation in the $\mathrm{F}$ regime.

IV.6. Discussion. We summarize the above analysis as three main findings:

(1) The stock-bond return correlation is positive in the M regime, mainly driven by the technology shock; this correlation is negative in the $\mathrm{F}$ regime, mainly driven by the investment shock.

(2) The consumption-inflation correlation is negative in the $\mathrm{M}$ regime, mainly driven by the technology shock; this correlation is positive in the F regime, mainly driven by the investment shock.

(3) Risk premiums of stocks and nominal long-term bonds are always positive in both the $\mathrm{M}$ and $\mathrm{F}$ regimes, mainly driven by the technology shock. 


\section{TABLE 3. Correlation matrix}

\begin{tabular}{l|ccccc}
\hline \hline Variables & $\begin{array}{c}r_{s}-r \\
(\mathrm{M} / \mathrm{F})\end{array}$ & $\begin{array}{c}r_{b}-r \\
(\mathrm{M} / \mathrm{F})\end{array}$ & $\begin{array}{c}\pi \\
(\mathrm{M} / \mathrm{F})\end{array}$ & $\begin{array}{c}\Delta c \\
(\mathrm{M} / \mathrm{F})\end{array}$ & $\begin{array}{c}m \\
(\mathrm{M} / \mathrm{F})\end{array}$ \\
\hline$r_{s}-r$ & 1.00 & $0.51 /-0.52$ & $-0.45 / 0.15$ & $0.52 / 0.58$ & $-0.66 /-0.37$ \\
$r_{b}-r$ & & 1.00 & $-0.42 /-0.12$ & $0.31 /-0.32$ & $-0.79 /-0.19$ \\
$\pi$ & & & 1.00 & $-0.73 / 0.05$ & $0.52 / 0.21$ \\
$\Delta c$ & & & & 1.00 & $-0.35 /-0.24$ \\
$m$ & & & & & 1.00 \\
\hline \hline
\end{tabular}

Notes: This table reports the correlation matrix of financial and macroeconomic variables with all four shocks in the baseline model. The variables include the excess return on stocks $\left(r_{s}-r\right)$, the excess return on the 5-year nominal bond $\left(r_{b}-r\right)$, inflation $(\pi)$, consumption growth $(\Delta c)$, and the pricing kernel $(m)$. The numbers before and after the slash $(/)$ represent the correlations in the $\mathrm{M}$ regime and the $\mathrm{F}$ regime.

It is informative to relate these findings to the Capital Asset Pricing Model (CAPM). In an economy where the CAPM holds, a negative correlation between returns on the nominal longterm bond and on the stock market implies negative excess bond risk premiums. However, as Fama and French (1993) show, the CAPM fails to explain empirical data. As shown in Belo et al. (2017), the CAPM also fails in models with multiple fundamental risks like ours or in models with the nonlinear pricing kernel In our model, because the risk premiums of stocks and long-term bonds are driven by the technology shock in both the $\mathrm{M}$ and $\mathrm{F}$ regimes, they are always positive regardless of regime. By contrast, the stock-bond return correlation, which has the same sign as the market beta of the long-term bond, turns negative in the $\mathrm{F}$ regime, because it is mainly driven by the investment shock in this regime. Such a coexistence of positive bond risk premium and negative stock-bond correlation is an innovation of our work relative to others.

The above analysis is confirmed by the simulation-based correlation matrix in Table 3 of the excess stock and long-term bond returns, inflation, consumption growth rate, and pricing kernel in both the $\mathrm{M}$ and $\mathrm{F}$ regimes, under the baseline model with all four shocks. The stock-bond return correlation is 0.51 under the $\mathrm{M}$ regime and -0.52 under the $\mathrm{F}$ regime; the consumption-inflation correlation is -0.73 under the $\mathrm{M}$ regime and 0.05 under the $\mathrm{F}$ regime; and the correlation between the pricing kernel and returns on stock (bond) are always negative under both the $\mathrm{M}$ and $\mathrm{F}$ regimes, -0.66 and $-0.37(-0.79$ and -0.19$)$, indicating positive risk premium in stock (bond).

ㅁi et al. (2018) show that the CAPM can fail even in models with only one fundamental shock containing disaster risk, because disaster risk generates a highly nonlinear pricing kernel. 


\section{Robustness}

V.1. The F regime at the zero lower bound (ZLB). The ZLB is an extreme case of the F regime, where the policy rate does not react to economic fluctuations at all, i.e., $\phi_{\pi}$ and $\phi_{y}$ are equal to zero. To keep the model tractable and avoid the computational difficulty, we do not include additional preference or inflation shocks to create the ZLB environment endogeneously. Instead, we assume the ZLB scenario exogeneously, in which the policy rate is almost constant at its steady state level (i.e., $\phi_{r}=0.99$ and $\phi_{\pi}=\phi_{y}=0$ ) ${ }^{10}$ The parameters in the fiscal policy rule are the same as in the $\mathrm{F}$ regime of our baseline model. Although the standard new Keynesian model generates some unpleasant features at or close to the ZLB 11 the negative correlation between returns on stocks and nominal bonds is robust to the value of $\phi_{\pi}$. In fact, as shown in Figures A.1 and A.2, both the investment shock and the technology shock generate a negative stock-bond return correlation at the ZLB for the following reason. Stock prices fall in response to a positive technology shock because of the lower consumption growth when the ZLB binds. As a result, the bond and stock returns move in opposite directions. Table A.2 reports the correlation matrix when the economy is constrained by the ZLB in the F regime. As one can see, the positive stock-bond return correlation and negative consumption-inflation correlation in the $\mathrm{M}$ regime and the negative stock-bond return correlation and positive consumption-inflation correlation in the F regime continue to hold.

V.2. Alternative preferences. In our baseline model, we use a recursive preference with habit formation to generate risk premiums with reasonable magnitude. We show in this section that the relation between key correlations and policy regime is robust to alternative preferences.

V.2.1. CRRA preference. Figures A.3 and A.4 display the impulse responses to technology and investment shocks in both policy regimes with the constant relative risk aversion (CRRA) preference. These results are qualitatively similar to those under the recursive preference in the baseline model. Specifically, a positive technology shock leads to an increase in returns on stocks (consumption claims) and the long-term nominal bond in both policy regimes, while a positive investment shock leads to opposite movements in these two returns. Panel A of

\footnotetext{
${ }^{10}$ Under this particular setup, the policy rate does not respond to inflation and output changes at all, but only fluctuates with moderate monetary policy shocks.

${ }^{11}$ When $\phi_{\pi}$ is smaller than a certain threshold, the model implies that consumption and output respond negatively to a positive technology shock. Because the policy rate is kept constant, lower inflation caused by a positive technology shock leads to higher real interest rate, which has a significant contractionary impact on the economy. This is one of the most important criticisms of the new Keynesian model with the ZLB.
} 
Table A.3 shows that the positive stock-bond return correlation and negative consumptioninflation correlation in the $\mathrm{M}$ regime and the opposite in the $\mathrm{F}$ regime still hold under the CRRA preference.

V.2.2. Recursive preference without habit. We solve a model under a recursive preference without a habit formation. Figures A.5 and A.6 report the impulse responses to technology and investment shocks in both policy regimes. Panel B of Table A.3 presents the correlation matrix under the recursive preference without the habit. The impulse responses and the correlation matrix are qualitatively similar to those of the baseline model.

V.3. An extended model with nine shocks. We extend our baseline model to include five additional shocks that are commonly used in the macro-finance literature: a transitory productivity shock, an investment-specific technological (IST) shock, a price markup shock, a wage markup shock, and a labor supply shock. We then calibrate the model to match moments of key macroeconomic and financial variables ${ }^{12}$ Table A.6 presents the stockbond return correlation and consumption-inflation correlation under each shock alone and Table A.7 presents the correlation matrix of key variables in the presence of all 9 shocks. Figures A.7 to A.15 report the impulse responses of key financial and macro variables under each of the nine shocks.

All newly added shocks, except the IST shock, imply positive stock-bond return correlation in the $\mathrm{M}$ regime, and all of them imply negative stock-bond return relation in the $\mathrm{F}$ regime. The impact of technology shock dominates that of the IST shock in our calibration, and thus the dependence of the stock-bond return relation on policy regimes continues to hold in the 9-shock model. In terms of the consumption-inflation correlation, all newly added shocks imply a positive correlation in the $\mathrm{M}$ regime, and all but the transitory productivity and price markup shocks imply a negative correlation in the F regime. Our calibration indicates that the investment shock continues to dominate the consumption-inflation correlation in the $\mathrm{F}$ regime.

In short, the added shocks do not change the dependence of the stock-bond return and consumption-inflation correlations on policy regimes in the baseline model as shown in Table A.7. In addition, stock and bond risk premiums remain positive under all policy regimes.

\section{Conclusion}

We apply a new Keynesian model with the recursive preference to interactions between monetary and fiscal policies to account for (1) the positive stock-bond return correlation and the negative consumption-growth correlation during 1971-2000 when monetary policy was active and fiscal policy was passive (the $\mathrm{M}$ regime), and (2) a sign change of these two

\footnotetext{
${ }^{12}$ See Appendix F for the moments of macroeconomic and financial variables in the extended model.
} 
correlations after 2000 when monetary policy was passive and fiscal policy was active (the F regime). Moreover, our model generates positive risk premiums of stocks and bonds in both policy regimes, consistent with the data. The key mechanism we find is that technology shocks drive the fluctuation of the economy in the $\mathrm{M}$ regime while investment shocks are a driving force in the $\mathrm{F}$ regime. Our findings lay a structural foundation for a generalequilibrium framework that bridges financial markets and monetary-fiscal policies. 


\section{REFERENCES}

Abel, Andrew, "Risk Premia and Term Premia in General Equilibrium," Journal of Monetary Economics, 1999, 43 (1), 3-33.

Andreasen, Martin, "An Estimated DSGE Model: Explaining Variation in Nominal Term Premia, Real Term Premia, and Inflation Risk Premia," European Economic Review, 2012, 56, 1656-1674.

Baele, Lieven, Geert Bekaert, and Koen Inghelbrecht, "The Determinants of Stock and Bond Return Comovements," The Review of Financial Studies, March 2010, 23 (6), 2374-2428.

Bai, Hang, Kewei Hou, Howard Kung, Erica X.N. Li, and Lu Zhang, "The CAPM strikes back? An equilibrium model with disasters," Journal of Financial Economics, 2018, 131(2), 269-298.

Belo, Frederico, Jun Li, Xiaoji Lin, and Xiaofei Zhao, "Labor-force Heterogeneity and asset prices: The importance of skilled labor," The Review of Financial Studies, 2017, 30(10), 3669-3709.

Bianchi, Francesco and Cosmin Ilut, "Monetary/Fiscal Policy Mix and Agents' Beliefs," Review of Economic Dynamics, 2017, 26, 113-139.

Binsbergen, Jules H. Van, Jesús Fernández-Villaverde, Ralph Koijen, and Juan Rubio-Ramírez, "The Term Structure of Interest Rates in a DSGE Model with Recursive Preferences," Journal of Monetary Economics, 2012, 59, 634-648.

Bretscher, Lorenzo, Alex Hsu, and Andrea Tamoni, "Level and volatility shocks to fiscal policy: term structure implications," 2018. Working Paper, Georgia Institute of Technology.

Calvo, Guillermo, "Staggered Prices in a Utility-Maximizing Framework," Journal of Monetary Economics, 1983, 12, 383-398.

Campbell, John Y., Adi Sunderam, and Luis M. Viceira, "Inflation bets or deflation hedges? The changing risks of nominal bonds.," Critical Finance Review, 2016, (forthcoming).

, Carolin Pflueger, and Luis M. Viceira, "Macroeconomic Drivers of Bond and Equity Risks," Journal of Political Economy, 2020. forthcoming.

Christiano, Lawrence J., Roberto Motto, and Massimo Rostagno, "Risk Shocks," American Economic Review, 2014, 104 (1), 27-65.

Christiansen, Charlotte and Angelo Ranaldo, "Realized bond-stock correlation: macroeconomic announcement effects," Journal of Futures Markets, 2007, (27), 439-469.

David, Alexander and Pietro Veronesi, "What ties return volatilities to fundamentals and price valuations?," Journal of Political Economy, 2013, (121), 682-746. 
Davig, Troy and Eric M. Leeper, "Monetary-Fiscal Policy Interactions and Fiscal Stimulus," European Economic Review, 2011, 55, 211-227.

Dew-Becker, Ian, "Bond Pricing with a Time-Varying Price of Risk in an Estimated Medium-Scale Bayesian DSGE Model," Journal of Money, Credit, and Banking, 2014, 46, $837-888$.

Fama, Eugene F. and Kenneth R. French, "Common Risk Factors in the Returns on Stocks and Bonds," Journal of Financial Economics, 1993, 33, 3-56.

Farmer, Roger E.A., Daniel F. Waggoner, and Tao Zha, "Minimal State Variable Solutions to Markov-Switching Rational Expectations Models," Journal of Economic Dynamics \& Control, 2011, 35, 2150-2166.

Foerster, Andrew, Juan F. Rubio-Ramírez, Daniel F. Waggoner, and Tao Zha, "Perturbation methods for Markov-switching dynamic stochastic general equilibrium models," Quantitative Economics, July 2016, 7 (2), 637-669.

Gourio, François and Phuong Ngo, "Risk premia at the ZLB: a macroeconomic interpretation," 2016. Working paper, Federal Reserve Bank of Chicago.

Guidolin, Massimo and Allan Timmermann, "Asset allocation under multivariate regime switching," Journal of Economic Dynamics and Control, 2007, (31), 3503-3544.

Gürkaynak, Refet S., Brian Sack, and Jonathan H. Wright, "Industry Concentration and Average Stock Returns," Journal of Finance, 08 2007, 61 (4), 1927-1956.

Hsu, Alex, Erica X.N. Li, and Francisco Palomino, "Real and nominal equilibrium yield curves," Management Science, 2019. forthcoming.

Justiniano, Alejandro, Giorgio E. Primiceri, and Andrea Tambalotti, "Investment shocks and business cycles," Journal of Monetary Economics, March 2010, 57 (2), 132-145. , and __ , "Investment shocks and the relative price of investment," Review of Economic Dynamics, January 2011, 14 (1), 102-121.

Kogan, Leonid and Dimitris Papanikolaou, "Firm Characteristics and Stock Returns: The Role of Investment-Specific Shocks," Review of Financial Studies, 2013, 26, 27182759 .

allocation, and growth," Quarterly Journal of Economics, 2017, 132, 665-712.

Kung, Howard, "Macroeconomic Linkages Between Monetary Policy and the Term Structure of Interest Rates," Journal of Financial Economics, 2015, 115, 42-57.

Leeper, Eric M., "Equilibria under 'active' and 'passive' monetary and fiscal policies," Journal of Monetary Economics, 1991, (27), 129-147.

, Nora Traum, and Todd B. Walker, "Clearing up the fiscal multiplier morass," American Economic Review, 2017, 55 (6), 2409-2454. 
Li, Erica X.N. and Francisco Palomino, "Nominal Rigidities, Asset Returns, and Monetary Policy," Journal of Monetary Economics, 2014, 66, 210-225.

McCulloch, J. Huston and H. Kwon, "U.S. term structure data, 1947-1991," 1993. Working Paper 93-6, Ohio State University.

Ohanian, Lee E., "The macroeconomic effects of war finance in the United States: World War II and the Korean War," American Economic Review, 1997, 87(1), 23-40.

Papanikolaou, Dimitris, "Investment Shocks and Asset Prices," Journal of Political Economy, 2011, 119 (4), 639-685.

Rudebusch, Glenn D. and Eric T. Swanson, "The Bond Premium in a DSGE Model with Long-Run Real and Nominal Risks," American Economic Journal: Macroeconomics, 2012, 4, 105-143.

Sargent, Thomas J. and Neil Wallace, "Some Unpleasant Monetarist Arithmetic," Federal Reserve Bank of Minneapolis Quarterly Review, Fall 1981, 5 (3), 1-17.

Sims, Christopher A., "Solving Linear Rational Expectations Models," Computational Economics, 2002, 20 (1), 1-20.

and Tao Zha, "Were There Regime Switches in US Monetary Policy?," American Economic Review, 2006, 91 (1), 54-81.

Smets, Frank and Rafael Wouters, "Shocks and Frictions in US Business Cycles: A Bayesian DSGE Approach," American Economic Review, June 2007, 97 (3), 586-606.

Song, Dongho, "Bond Market Exposures to Macroeconomic and Monetary Policy Risks," The Review of Financial Studies, August 2017, 30 (8), 2761-2817.

Taylor, John B., "Discretion versus Policy Rules in Practice," Carnegie-Rochester Conference Series on Public Policy, December 1993, 39 (1), 195-214.

Woodford, Michael, "Fiscal requirements for price stability," Journal of Money, Credit and Banking, 2001, 33, 669-728. 


\section{Appendix A. DATA}

The raw data in quarterly frequency used for constructing the moments of key macro and finance variables:

GDP Deflator $(P)$ : price index of nominal gross domestic product, index numbers, $2005=100$, seasonally adjusted, NIPA.

Nominal nondurable consumption $\left(C_{\text {nondurables }}^{\text {nom }}\right)$ : nominal personal consumption expenditures: nondurable goods, billions of dollars, seasonally adjusted at annual rates, NIPA.

Nominal durable consumption $\left(C_{\text {durables }}^{\text {nom }}\right)$ : nominal personal consumption expenditures: durable goods, billions of dollars, seasonally adjusted at annual rates, NIPA.

Nominal consumption services $\left(C_{\text {services }}^{\text {nom }}\right)$ : nominal personal consumption expenditures: services, billions of dollars, seasonally adjusted at annual rates, NIPA.

Nominal investment $\left(I^{\text {nom }}\right)$ : nominal gross private domestic investment, billions of dollars, seasonally adjusted at annual rates, NIPA.

Price index $\left(P C^{n o m}\right)$ : price index of nondurable goods, index numbers, $2005=100$, seasonally adjusted at annual rates, NIPA.

Price index $\left(P I^{n o m}\right)$ : nominal investment: price index of nominal gross private domestic investment, Nonresidential, Equipment \& Software index numbers, $2005=100$, seasonally adjusted at annual rates, NIPA.

Federal Funds Rate $(F F)$ : effective federal funds rate, percent, FRED2.

Shadow Rate $(S R)$ : shadow federal funds rate, percent, Atlanta Fed.

Federal Debt $(B / Y)$ : total public debt as percent of gross domestic product, percent of GDP, seasonally adjusted, FRED2.

Here NIPA, BLS, FRED2, and Atlanta Fed stand for

FRED2: Database of the Federal Reserve Bank of St. Louis available at:

http://research.stlouisfed.org/fred2/

BLS: Database of the Bureau of Labor Statistics available at: http://www.bls.gov/

NIPA: Database of the National Income And Product Accounts available at:

http://www.bea.gov/national/nipaweb/index.asp.

Atlanta Fed: Database of the Center for Quantitative Economic Research (CQER) of the Federal Reserve Bank of Atlanta available at: https://www.frbatlanta.org/cqer.aspx.

The financial market data used include:

Stock return: Market portfolio excess return, percent, Kenneth French's website.

5-yr nominal bond: 5-year nominal Treasury bonds yield, percent, Gürkaynak et al. (2007).

Here Kenneth French's website, WRDS and McCulloch and Kwon (1993) stand for

Kenneth French's website: Kenneth French's data library available at:

http://mba.tuck.dartmouth.edu/pages/faculty/ken.french/data_library.html.

Gürkaynak et al. (2007): Daily yields on nominal and real Treasury bonds with maturity ranging from one to 20 years, 1961 to present, available at:

https://Www.federalreserve.gov/econres/feds/2006.htm

ApPEndix B. A RETURn REPRESEntation OF PRICING KERNEL

Define $\tilde{V}_{t}=\mathbb{E}_{t}\left[V_{t+1}^{\frac{1-\gamma}{1-\psi}}\right]$ and

$$
\begin{aligned}
\beta \tilde{V}_{t}^{\frac{1-\psi}{1-\gamma}} & =\beta \tilde{V}_{t} \tilde{V}_{t}^{-\frac{\psi-\gamma}{1-\gamma}}=\mathbb{E}_{t}\left[V_{t+1} V_{t+1}^{\frac{\psi-\gamma}{1-\psi}} \tilde{V}_{t}^{-\frac{\psi-\gamma}{1-\gamma}}\right] \\
& =C_{h, t}^{-\psi} \mathbb{E}_{t}\left[M_{t, t+1} C_{h, t+1}^{\psi} V_{t+1}\right]
\end{aligned}
$$


where the last equality comes from the definition of the pricing kernel

$$
M_{t, t+1}=\beta\left(\frac{C_{h, t+1}}{C_{h, t}}\right)^{-\psi}\left(\frac{V_{t+1}}{\tilde{V}_{t}^{\frac{1-\psi}{1-\gamma}}}\right)^{\frac{\psi-\gamma}{1-\psi}} .
$$

The above result leads to

and

$$
\beta C_{h, t}^{\psi} \tilde{V}_{t}^{\frac{1-\psi}{1-\gamma}}=\mathbb{E}_{t}\left[M_{t, t+1} C_{h, t+1}^{\psi} V_{t+1}\right]
$$

$$
C_{h, t}^{\psi} V_{t}=(1-\beta) C_{h, t}^{\psi} U_{t}+\mathbb{E}_{t}\left[M_{t, t+1} C_{h, t+1}^{\psi} V_{t+1}\right]
$$

Define

$$
D_{u, t}=(1-\psi) C_{h, t}^{\psi} U_{t} \quad \text { and } \quad P_{u, t}=\frac{1-\psi}{1-\beta} C_{h, t}^{\psi} V_{t}
$$

we can rewrite equation (B.1) as

$$
P_{u, t}=D_{u, t}+\mathbb{E}_{t}\left[M_{t, t+1} P_{u, t+1}\right] \Rightarrow \mathbb{E}_{t}\left[M_{t, t+1} R_{u, t+1}\right]=1
$$

where

$$
R_{u, t+1}=\frac{P_{u, t+1}}{P_{u, t}-D_{u, t}}=\frac{C_{h, t+1}^{\psi} V_{t+1}}{\beta C_{h, t}^{\psi} \tilde{V}_{t}^{\frac{1-\psi}{1-\gamma}}}=\beta^{-1}\left(\frac{C_{h, t+1}}{C_{h, t}}\right)^{\psi}\left(\frac{V_{t+1}}{\tilde{V}_{t}^{\frac{1-\psi}{1-\gamma}}}\right) .
$$

It can be easily shown that the pricing kernel can be written as

$$
M_{t, t+1}=\left[\beta\left(\frac{C_{h, t+1}}{C_{h, t}}\right)^{-\psi}\right]^{\frac{1-\gamma}{1-\psi}} R_{u, t+1}^{\frac{\psi-\gamma}{1-\psi}}
$$

Next we show that $D_{u, t}$ can be written as the combination of consumption and labor income.

$$
\begin{aligned}
D_{u, t} & =C_{h, t}-\frac{1-\psi}{1+\phi} A_{L, t} C_{h, t+1}^{\psi} L_{t}^{1+\phi}\left(\frac{\hat{W}_{t}}{W_{t}}\right)^{\frac{\lambda_{w}(1+\phi)}{1-\lambda w}} \\
& =C_{h, t}-\frac{L_{t} W_{t}}{P_{t}} \Theta_{t}
\end{aligned}
$$

where

$$
\Theta_{t} \equiv \frac{1-\psi}{1+\phi} \frac{1}{\mu_{w, t}} \frac{J_{w, t}}{H_{w, t}}\left(\frac{W_{t}^{*}}{W_{t}}\right)^{1-\phi \sigma_{w, t}}\left(\frac{\hat{W}_{t}}{W_{t}}\right)^{\frac{\lambda w(1+\phi)}{1-\lambda_{w}}} .
$$

The dividend $D_{u, t}$ can be interpreted as consumption minus the disutility of labor in monetary terms.

We can express $m_{t, t+1} \equiv \log M_{t, t+1}$ in terms of $\tilde{P}_{u, t+1}=P_{u, t+1} / D_{u, t+1}$ and $\tilde{d}_{u, t+1} \equiv \log \left(D_{u, t+1} / C_{h, t+1}\right)=$ $\log \left(1-\frac{L_{t+1} W_{t+1}}{C_{h, t+1} P_{t+1}} \Theta_{t}\right)$ :

$$
m_{t, t+1}=\theta \log \beta-\gamma \Delta c_{h, t+1}-(1-\theta) \Delta \tilde{d}_{u, t+1}-(1-\theta) \log \left(\frac{\tilde{P}_{u, t+1}}{\tilde{P}_{u, t}-1}\right),
$$

where $\theta \equiv \frac{1-\gamma}{1-\psi}$. We can further decompose the pricing kernel into short- and long-run components as $m_{t, t+1}^{S R}=-\gamma \Delta c_{h, t+1}-(1-\theta) \Delta \tilde{d}_{u, t+1}$ and $m_{t, t+1}^{L R}=-(1-\theta) \log \left(\frac{\tilde{P}_{u, t+1}}{\tilde{P}_{u, t}-1}\right)$, respectively, so that

$$
m_{t, t+1}=\theta \log \beta+m_{t, t+1}^{S R}+m_{t, t+1}^{L R} .
$$

We can further show that $\tilde{P}_{u, t}$ is the sum of all future consumption growth and the growth rate of $\tilde{d}_{u, t}$, which depends on the change in labor income-to-consumption ratio:

$$
\begin{aligned}
\tilde{P}_{u, t} & =1+\mathbb{E}_{t}\left[e^{m_{t, t+1}+\Delta c_{h, t+1}+\Delta \tilde{d}_{u, t+1}} \tilde{P}_{u, t+1}\right] \\
& =1+\sum_{s=1}^{\infty} \mathbb{E}_{t}\left[e^{m_{t, t+s}+\Delta c_{h, t, t+s}+\Delta \tilde{d}_{u, t, t+s}}\right]
\end{aligned}
$$


where $\Delta c_{h, t, t+s}=\sum_{\tau=1}^{s} \Delta c_{h, t+\tau}$ and $\Delta \tilde{d}_{h, t, t+s}=\sum_{\tau=1}^{s} \Delta \tilde{d}_{h, t+\tau}$. If we define $\tilde{r}_{u, t+1} \equiv \log R_{u, t+1}-\Delta c_{h, t+1}$, the pricing kernel can be written as

$$
m_{t, t+1}=\theta \log \beta-\gamma \Delta c_{h, t+1}-(1-\theta) \tilde{r}_{u, t+1} .
$$

\section{Appendix C. Yield and Duration}

The yield of the long-term bond with decay coefficient $\rho$ is $\iota=1 / P_{b}-(1-\rho)$ where $P_{b}$ is the price of the bond.

$$
\begin{aligned}
P_{b} & =\frac{1}{1+\iota}+\frac{\rho}{(1+\iota)^{2}}+\cdots+\frac{\rho^{t}}{(1+\iota)^{t+1}}+\cdots \\
& =\frac{1}{1+\iota} \times \frac{1}{1-\rho /(1+\iota)} \\
& =\frac{1}{1+\iota-\rho} \\
\Rightarrow \iota & =1 / P_{b}-(1-\rho) .
\end{aligned}
$$

It's easy to show that for continuously-compounded yield $\tilde{\iota}=\ln \left(1 / P_{b}+\rho\right)$. The consol bond has no finite maturity, however, we can compute its duration. The duration of the consol is given by

$$
\begin{aligned}
D & =\frac{1}{P_{b}}\left[1 \times \frac{1}{1+\iota}+2 \times \frac{\rho}{(1+\iota)^{2}}+\cdots+(t+1) \times \frac{\rho^{t}}{(1+\iota)^{t+1}}+\cdots\right] \\
& =\frac{1}{P_{b}} \frac{1}{1+\iota}\left[1+2 \frac{\rho}{1+\iota}+\cdots\right] \\
& =\frac{1}{P_{b}} \frac{1}{1+\iota} \frac{\partial}{\partial(\rho /(1+\iota))}\left[\frac{1}{1-\rho /(1+\iota)}-1\right] \\
& =\frac{1}{1-\rho /(1+\iota)}
\end{aligned}
$$

We can also express the relationship between the expected yield and return of a real consol bond. By definition, the expected yield and return on a consol bond is given by

$$
\begin{aligned}
\mathbb{E}\left[\iota_{t}\right] & =\mathbb{E}\left[1 / P_{b, t}\right]-(1-\rho) \\
\mathbb{E}\left[\log R_{b, t}\right] & =\mathbb{E}\left[\frac{1+\rho P_{b, t}}{P_{b, t-1}}\right]-1 \\
& =\mathbb{E}\left[1 / P_{b, t-1}\right]+\rho \mathbb{E}\left[\frac{P_{b, t}}{P_{b, t-1}}\right]-1 .
\end{aligned}
$$

It's straightforward to show that

Similarly we get

$$
\mathbb{E}\left[\iota_{t}\right]=\mathbb{E}\left[\log R_{b, t}\right]+\rho\left(1-\mathbb{E}\left[\frac{P_{b, t}}{P_{b, t-1}}\right]\right) .
$$

$$
\mathbb{E}\left[\iota_{t}^{\$}\right]=\mathbb{E}\left[\log R_{b, t}^{\$}\right]+\rho\left(1-\mathbb{E}\left[\frac{P_{b, t}^{\$}}{P_{b, t-1}^{\$}}\right]\right) .
$$

ApPENDix D. Risk PREMIUM IN LONG-TERM NOMINAL ZERO-COUPON BONDS

Nominal default-free, zero-coupon bonds with maturity $n$ pay a unit of real and nominal consumption, respectively, at maturity. Their prices are

$$
P_{b, t}^{(n)} \equiv e^{-n \iota_{t}^{(n)}}=\mathbb{E}_{t}\left[e^{m_{t, t+n}}\right]
$$

in which $m_{t, t+n}=\sum_{i=1}^{n} m_{t+i}$, and $\iota_{t}^{(n)}$ is the yield on the bond. In order to illustrate the mechanism that drives the return on long-term bonds, we derive the bond risk premium analytically under the simplifying assumption that all the variables follow log-normal distribution and are homoscedastic. In equilibrium, $\log$ 
return on bond, $r_{b, t+1}^{(n)}=\log \exp \left(-(n-1) \iota_{t+1}^{(n-1)}+n \iota_{t}^{(n)}\right)$, satisfies $\mathbb{E}_{t}\left[e^{m_{t+1} r_{b, t+1}^{(n)}}\right]=1$, which leads to

$$
\log \mathbb{E}_{t}\left[e^{r_{b, t+1}^{(n)}-r_{t}}\right]=\operatorname{cov}_{t}\left(m_{t+1},(n-1) \iota_{t+1}^{(n-1)}\right) .
$$

By the definition of bond price, we have

$$
\log P_{t+1}^{(n-1)}=-(n-1) \iota_{t}^{(n-1)}=\log \mathbb{E}_{t+1}\left[e^{\sum_{i=2}^{n} m_{t+i}}\right]=\mathbb{E}_{t+1}\left[\sum_{i=2}^{n} m_{t+i}\right]+\frac{1}{2} \operatorname{var}_{t+1}\left(\sum_{i=2}^{n} m_{t+i}\right)
$$

Substituting Equation D.3 into Equation D.2 we have

$$
\log \mathbb{E}_{t}\left[e^{r_{b, t+1}^{(n)}-r_{t}}\right]=-\operatorname{cov}_{t}\left(m_{t+1}, \sum_{j=2}^{n} m_{t+j}\right)=\operatorname{cov}_{t}\left(m_{t+1}, \sum_{j=1}^{n-1} r_{t+j}\right)
$$

which utilizes the fact that under the assumption of log-normality and homoscedasticity, variance and covariance are constant.

\section{Appendix E. Correlation of two endogenous variables}

Under loglinear approximation, any endogenous variable $r$ (log deviation from its steady state value) can be written as

$$
r_{t+1}=A(s) x_{t}+H(s) \mathcal{E}_{t+1}
$$

where $x_{t+1}$ is vector of the state variables, $\mathcal{E}_{t+1}$ is the vector of exogenous shocks, and $A(s)$ and $H(s)$ are coefficient matrices depending on regime $s$. The correlation between any two variables $r_{1, t+1}$ and $r_{2, t+1}$ is given by

$$
\begin{aligned}
& \operatorname{Corr}_{t}\left(r_{1, t+1}, r_{2, t+1}\right)=\frac{\operatorname{Cov}_{t}\left(r_{1, t+1}, r_{2, t+1}\right)}{\sqrt{\operatorname{Var}_{t}\left(r_{1, t+1}\right) \operatorname{Var}_{t}\left(r_{2, t+1}\right)}} \\
& =\frac{\sum_{e=1}^{n^{s}} h_{1, e} h_{2, e} \sigma_{e}^{2}}{\sqrt{\sum_{e=1}^{n^{s}} h_{1, e}^{2} \sigma_{e}^{2}} \sqrt{\sum_{e=1}^{n^{s}} h_{2, e}^{2} \sigma_{e}^{2}}} \\
& =\sum_{e=1}^{n^{s}} \mathcal{S}\left(h_{1, e} h_{2, e}\right) \sqrt{\frac{h_{1, e}^{2} \sigma_{e}^{2}}{\sum_{e=1}^{n^{s}} h_{1, e}^{2} \sigma_{e}^{2}}} \sqrt{\frac{h_{2, e}^{2} \sigma_{e}^{2}}{\sum_{e=1}^{n^{s}} h_{2, e}^{2} \sigma_{e}^{2}}} \\
& =\sum_{e=1}^{n^{s}} \mathcal{S}\left(h_{1, e}\right) \mathcal{S}\left(h_{2, e}\right) \sqrt{\mathcal{V}_{1, e} \mathcal{V}_{2, e}},
\end{aligned}
$$

where $h_{1, e}$ is the matrix element in $H(s)$ corresponding to $r_{1}$ and shock $e, n^{s}$ is the number of shocks, $\sigma_{e}$ is the standard deviation of shock $e, \mathcal{V}_{1, e}$ is the contribution of shock $e$ to the variance of $r_{1}$ and $\mathcal{S}\left(h_{1, e}\right)$ is the sign of $h_{1, e}$. Similar definitions apply to $h_{2, e} \mathcal{V}_{2, e}$, and $\mathcal{S}\left(h_{2, e}\right)$.

It is straightforward to show that the covariance between the pricing kernel $m$ and return $r$ is given by

$$
\operatorname{Cov}_{t}(m, r)=\sigma_{m} \sigma_{r} \sum_{i=1}^{n^{s}} \mathcal{S}\left(h_{m, i}\right) \mathcal{S}\left(h_{r, i}\right) \sqrt{\mathcal{V}_{m, i} \mathcal{V}_{r, i}} .
$$

\section{Appendix F. Additional shocks}

Instead of assuming a constant growth rate of relative price of investment good $\left(\mu^{\Psi}\right)$, total factor productivity $(\omega)$, substitutability among differentiated intermediate goods and labor $\left(\lambda_{p}\right.$ and $\left.\lambda_{w}\right)$, and disutility of working $\left(a^{L}\right)$ as in the baseline model, now we assume that they face exogenous shocks and follow $\operatorname{AR}(1)$ processes with persistence $\rho_{x}$ 's and standard deviation $\sigma_{x}$ 's ${ }^{13}$

The growth rate of relative price of investment good, $\mu_{t}^{\Psi}$, evolves as follows:

$$
\mu_{t}^{\Psi}=\mu_{\Psi}\left(1-\rho_{\Psi}\right)+\rho_{\Psi} \mu_{t-1}^{\Psi}+\sigma_{\Psi} e_{t}^{\Psi}, \quad \text { and } e_{t}^{\Psi} \sim \operatorname{IIDN}(0,1),
$$

where $e_{t}^{\psi}$ denotes the investment-specific technology (IST) shock.

\footnotetext{
${ }^{13}$ Calibrated parameter values of the shock processes and the resulting simulated moments of key macro and financial variables are presented in Table A.4 and Table A.5. respectively.
} 
Total factor productivity, $\omega_{t}$, faces a transitory productivity shock $e_{t}^{\omega}$ :

$$
\log \left(\frac{\omega_{t}}{\omega}\right)=\rho_{\omega} \log \left(\frac{\omega_{t-1}}{\omega}\right)+\sigma_{\omega} e_{t}^{\omega}, \quad \text { and } e_{t}^{\omega} \sim \operatorname{IID\mathcal {N}}(0,1),
$$

Substitutability of differentiated goods and labor faces price markup and wage markup shocks, respectively:

$$
\begin{aligned}
& \log \left(\frac{\lambda_{t}^{p}}{\lambda^{p}}\right)=\rho_{\lambda^{p}} \log \left(\frac{\lambda_{t-1}^{p}}{\lambda^{p}}\right)+\sigma_{\lambda^{p}} e_{t}^{\lambda^{p}}, \quad \text { and } e_{t}^{\lambda^{p}} \sim \operatorname{IIDN}(0,1), \\
& \log \left(\frac{\lambda_{t}^{w}}{\lambda^{w}}\right)=\rho_{\lambda^{w}} \log \left(\frac{\lambda_{t-1}^{w}}{\lambda^{w}}\right)+\sigma_{\lambda^{w}} e_{t}^{\lambda^{w}}, \quad \text { and } e_{t}^{\lambda^{w}} \sim \operatorname{IIDN}(0,1),
\end{aligned}
$$

where $e_{t}^{\lambda^{p}}$ and $e_{t}^{\lambda^{w}}$ denotes the price markup (PM) and wage markup (WM) shocks.

Disutility of working, $a_{t}^{L}$ evolves as follows:

$$
\log \left(\frac{a_{t}^{L}}{a^{L}}\right)=\rho_{a^{L}} \log \left(\frac{a_{t-1}^{L}}{a^{L}}\right)+\sigma_{a^{L}} e_{t}^{a^{L}}, \quad \text { and } e_{t}^{a^{L}} \sim \operatorname{IID} \mathcal{N}(0,1),
$$

where $e_{t}^{a^{L}}$ denotes the labor supply (LS) shock. 
TABlE A.1. Parameter values in the baseline model

\begin{tabular}{|c|c|c|}
\hline Parameter & Description & Value \\
\hline \multicolumn{3}{|c|}{ Panel A: Preference } \\
\hline$\beta$ & discount factor & 0.9988 \\
\hline$\psi$ & reciprocal of elasticity of intertemporal substitution & $1 / 1.2$ \\
\hline$\gamma$ & risk aversion & 60 \\
\hline$\phi$ & labor supply aversion & 1 \\
\hline$b_{h}$ & habit parameter & 0.85 \\
\hline \multicolumn{3}{|c|}{ Panel B: Production } \\
\hline$\alpha$ & capital share & 0.33 \\
\hline$\delta$ & capital depreciation rate & 0.025 \\
\hline$\sigma_{s}$ & investment adjustment cost parameter & 10.78 \\
\hline$\sigma_{a}$ & utilization rate cost parameter & 2.54 \\
\hline$\xi_{p}$ & probability that cannot re-optimize price & 0.74 \\
\hline$\ell$ & price indexation parameter & 0.90 \\
\hline$\lambda_{p}$ & degree of elasticity of substitution for goods aggregation & 1.9092 \\
\hline$\xi_{w}$ & probatility that cannot re-optimize wage & 0.81 \\
\hline$\ell_{w}$ & wage indexation parameter & 0.49 \\
\hline$\lambda_{w}$ & degree of elasticity of substitution for labor aggregation & 1.05 \\
\hline$\omega$ & total factor productivity & 1 \\
\hline$\mu^{z^{+}}$ & growth rate of the economy & 0.0044 \\
\hline$\mu^{\Psi}$ & growth rate of investment specific technology & 0.0017 \\
\hline$\pi^{*}$ & target inflation rate & 1.0065 \\
\hline$W^{e}$ & transfer received by entrepreneurs & 0.003 \\
\hline$\mu_{b}$ & bankruptcy cost & 0.31 \\
\hline$R$ & steady-state nominal interest rate & 1.0116 \\
\hline$\rho$ & decay rate of long-term government bonds coupon payment & 0.9627 \\
\hline$\lambda$ & leverage ratio & 1.5 \\
\hline$b^{\infty}$ & government-debt-to-GDP ratio & 0.55 \\
\hline \multicolumn{3}{|c|}{ Panel C: Policies } \\
\hline$\phi_{\pi}^{1}$ & sensitivity of interest rate to inflation (M regime) & 2.7372 \\
\hline$\phi_{\pi}^{2}$ & sensitivity of interest rate to inflation (F regime) & 0.4991 \\
\hline$\phi_{y}^{1}$ & sensitivity of interest rate to output (M regime) & 0.7037 \\
\hline$\phi_{y}^{2}$ & sensitivity of interest rate to output ( $\mathrm{F}$ regime) & 0.01520 \\
\hline$\phi_{r}^{1}$ & interest rate persistence ( $\mathrm{M}$ regime) & 0.91 \\
\hline$\phi_{r}^{2}$ & interest rate persistence ( $\mathrm{F}$ regime) & 0.6565 \\
\hline$\varsigma_{b}^{1}$ & sensitivity of tax to debt ( $\mathrm{M}$ regime) & 0.0609 \\
\hline$\varsigma_{b}^{2}$ & sensitivity of tax to debt ( $\mathrm{F}$ regime) & 0 \\
\hline$\varsigma_{y}^{1}$ & sensitivity of tax to output ( $\mathrm{M}$ regime) & 0.3504 \\
\hline$\varsigma_{y}^{2}$ & sensitivity of tax to output ( $\mathrm{F}$ regime) & 0.3504 \\
\hline$\varsigma_{g}^{1}$ & sensitivity of tax to government spending (M regime) & 0.3677 \\
\hline$\varsigma_{g}^{2}$ & sensitivity of tax to government spending (F regime) & 0.3677 \\
\hline$\varsigma_{\tau}^{1}$ & tax persistence (M regime) & 0.9844 \\
\hline$\varsigma_{\tau}^{2}$ & tax persistence ( $\mathrm{F}$ regime) & 0.8202 \\
\hline$g_{y}$ & steady-state government-spending-to-output ratio & 0.18 \\
\hline \multicolumn{3}{|c|}{ Panel D: Shocks } \\
\hline$\rho_{\mu^{z}}$ & persistence of the NT shock & 0.15 \\
\hline$\rho_{\zeta^{I}}$ & persistence of the MEI shock & 0.65 \\
\hline$\sigma_{\mu^{z}}$ & standard deviation of the NT shock & 0.821 \\
\hline
\end{tabular}


Table A.1 - continued from previous page

\begin{tabular}{llc}
\hline \hline Parameter & Description & Value \\
\hline$\sigma_{\zeta^{I}}$ & standard deviation of the MEI shock & 3.101 \\
$\sigma_{r}$ & standard deviation of the MP shock & 0.061 \\
$\sigma_{\tau}$ & standard deviation of the FP shock & 0.121 \\
\hline \hline
\end{tabular}


THE BOND MARKET AND FISCAL-MONETARY POLICY

\section{TABLE A.2. Correlation matrix - ZLB}

\begin{tabular}{c|ccccc}
\hline \hline Variables & $\begin{array}{c}r_{s}-r \\
(\mathrm{M} / \mathrm{F})\end{array}$ & $\begin{array}{c}r_{b}-r \\
(\mathrm{M} / \mathrm{F})\end{array}$ & $\begin{array}{c}\pi \\
(\mathrm{M} / \mathrm{F})\end{array}$ & $\begin{array}{c}\Delta c \\
(\mathrm{M} / \mathrm{F})\end{array}$ & $\begin{array}{c}m \\
(\mathrm{M} / \mathrm{F})\end{array}$ \\
\hline$r_{s}-r$ & 1.00 & $0.48 /-0.35$ & $-0.48 / 0.45$ & $0.51 / 0.59$ & $-0.68 / 0.70$ \\
$r_{b}-r$ & & 1.00 & $-0.45 /-0.15$ & $0.26 /-0.21$ & $-0.59 /-0.08$ \\
$\pi$ & & & 1.00 & $-0.75 / 0.30$ & $0.53 / 0.37$ \\
$\Delta c$ & & & & 1.00 & $-0.33 / 0.44$ \\
$m$ & & & & 1.00 \\
\hline \hline
\end{tabular}

Notes: This table reports the correlation matrix of financial and macroeconomic variables with all shocks in the model with the $\mathrm{F}$ regime at the ZLB. The variables include excess return on stock (claim on consumption) $\left(r_{s}-r\right)$, excess return on 5 -year nominal bond $\left(r_{b}-r\right)$, inflation $(\pi)$, consumption growth $(\Delta c)$, and pricing kernel $(m)$. The numbers before and after the slash $(/)$ represent the correlations in the $\mathrm{M}$ regime and $\mathrm{F}$ regime, respectively. 


\section{TABLE A.3. Correlation matrices - alternative preferences}

Panel A: CRRA preference

\begin{tabular}{c|ccccc}
\hline \hline Variables & $r_{s}-r$ & $r_{b}-r$ & $\pi$ & $\Delta c$ & $m$ \\
& $(\mathrm{M} / \mathrm{F})$ & $(\mathrm{M} / \mathrm{F})$ & $(\mathrm{M} / \mathrm{F})$ & $(\mathrm{M} / \mathrm{F})$ & $(\mathrm{M} / \mathrm{F})$ \\
\hline$r_{s}-r$ & 1.00 & $0.53 /-0.51$ & $-0.46 / 0.15$ & $0.52 / 0.58$ & $-0.96 /-0.98$ \\
$r_{b}-r$ & & 1.00 & $-0.42 /-0.12$ & $0.31 /-0.31$ & $-0.46 / 0.51$ \\
$\pi$ & & & 1.00 & $-0.73 / 0.06$ & $0.31 /-0.35$ \\
$\Delta c$ & & & & 1.00 & $-0.40 /-0.53$ \\
$m$ & & & & & 1.00 \\
\hline \hline
\end{tabular}

Panel B: Recursive preference without habit formation

\begin{tabular}{c|ccccc}
\hline \hline Variables & $r_{s}-r$ & $r_{b}-r$ & $\pi$ & $\Delta c$ & $m$ \\
& $(\mathrm{M} / \mathrm{F})$ & $(\mathrm{M} / \mathrm{F})$ & $(\mathrm{M} / \mathrm{F})$ & $(\mathrm{M} / \mathrm{F})$ & $(\mathrm{M} / \mathrm{F})$ \\
\hline$r_{s}-r$ & 1.00 & $0.11 /-0.49$ & $0.22 / 0.22$ & $0.97 / 0.97$ & $-0.39 /-0.39$ \\
$r_{b}-r$ & & 1.00 & $-0.22 /-0.22$ & $0.10 /-0.46$ & $-0.24 /-0.24$ \\
$\pi$ & & & 1.00 & $-0.44 / 0.00$ & $0.18 / 0.19$ \\
$\Delta c$ & & & & 1.00 & $-0.41 /-0.41$ \\
$m$ & & & & & 1.00 \\
\hline \hline
\end{tabular}

Notes: Panels A and B of this table report the correlation matrices of financial and macroeconomic variables in the models with CRRA preference and recursive preference without habit formation, respectively. The variables include excess return on stock $\left(r_{s}-r\right)$, excess return on 5 -year nominal bond $\left(r_{b}-r\right)$, inflation $(\pi)$, consumption growth $(\Delta c)$, and pricing kernel $(m)$. The numbers before and after the slash $(/)$ represent the correlations in the $\mathrm{M}$ regime and $\mathrm{F}$ regime, respectively.

\section{TABLE A.4. Parameter values for additional shock processes}

\begin{tabular}{ccc}
\hline \hline Parameters & Description & Value \\
\hline$\rho_{\mu^{\psi}}$ & persistence of the IST shock & 0.16 \\
$\rho_{\omega}$ & persistence of the TP shock & 0.81 \\
$\rho_{\lambda^{p}}$ & persistence of the PM shock & 0.91 \\
$\rho_{\lambda^{w}}$ & persistence of the WM shock & 0.90 \\
$\rho_{a^{L}}$ & persistence of the LS shock & 0.80 \\
$\sigma_{\mu^{\psi}}$ & standard deviation of the IST shock & 0.40 \\
$\sigma_{\omega}$ & standard deviation of the TP shock & 0.46 \\
$\sigma_{\lambda^{p}}$ & standard deviation of the PM shock & 0.22 \\
$\sigma_{\lambda^{w}}$ & standard deviation of the WP shock & 0.31 \\
$\sigma_{a^{L}}$ & standard deviation of the LS shock & 0.50 \\
\hline
\end{tabular}

Notes: This table reports the persistence and standard deviation of additional shock processes in the extended model. Parameters are calibrated according to Justiniano et al. (2011) and Christiano et al. (2014). 


\section{TABle A.5. Simulated moments with 9 shocks}

\begin{tabular}{lccccc}
\hline \hline \multirow{2}{*}{ Variables } & \multicolumn{2}{c}{ Data } & & \multicolumn{2}{c}{ Model } \\
\cline { 2 - 3 } \cline { 5 - 6 } & Mean & Std.Dev. & & Mean & Std.Dev. \\
\hline consumption growth $(\Delta c)$ & 1.41 & 1.78 & & 1.77 & 2.32 \\
investment growth $(\Delta i)$ & 2.43 & 11.62 & & 2.43 & 11.30 \\
inflation $(\pi)$ & 2.66 & 1.80 & & 2.67 & 2.32 \\
nominal short-term interest rate $(r)$ & 4.66 & 4.42 & & 4.64 & 1.75 \\
excess return on stock (consumption claim, $\left.r_{s}-r\right)$ & 7.99 & 16.68 & & 3.14 & 5.45 \\
excess return on 5-year nominal bond $\left(r_{b}-r\right)$ & 2.62 & 6.18 & & 0.65 & 1.61 \\
\hline
\end{tabular}

Notes: This table reports the first and second moments of key macroeconomic and financial variables. Column 1 is variable names. Columns 2 and 3 give the annualized mean and standard deviation in the data in percentage. Columns 4 and 5 give the corresponding simulated mean and standard deviation from the model.

\section{TABLE A.6. Correlations under each of the 9 shocks}

\begin{tabular}{l|cc}
\hline \hline Shocks & $\operatorname{corr}\left(r_{s}-r, r_{b}-r\right)$ & $\operatorname{corr}(\Delta c, \pi)$ \\
& $(\mathrm{M} / \mathrm{F})$ & $(\mathrm{M} / \mathrm{F})$ \\
\hline Technology & $0.99 / 0.93$ & $-0.93 /-0.82$ \\
Investment & $-0.31 /-0.70$ & $-0.53 / 0.26$ \\
Monetary policy & $0.99 / 0.91$ & $0.62 / 0.52$ \\
Fiscal policy & $-0.02 /-0.25$ & $-0.32 / 0.60$ \\
Total factor productivity & $0.96 /-0.48$ & $-0.85 /-0.68$ \\
Investment specific technology & $-0.50 /-0.76$ & $-0.25 / 0.55$ \\
Price markup & $0.93 /-0.56$ & $-0.87 /-0.43$ \\
Wage markup & $0.64 /-0.57$ & $-0.80 / 0.31$ \\
Labor supply & $0.79 /-0.56$ & $-0.88 / 0.16$ \\
\hline \hline
\end{tabular}

Notes: This table reports the stock-bond correlation $\left(\operatorname{corr}\left(r_{s}-r, r_{b}-r\right)\right)$, and consumption-growth-inflation correlation $(\operatorname{corr}(\Delta c, \pi))$, generated by each of the 9 shocks in the extended model. The 9 shocks are: technology shock, investment shock, total factor productivity (TP) shock, investment-specific technology shock (IST), price markup (PM) shock, wage markup (WM) shock, labor supply (LS) shock, monetary policy (MP) shock, and fiscal policy (FP) shock. The numbers before and after the slash (/) represent the correlations in the $\mathrm{M}$ regime and $\mathrm{F}$ regime, respectively. 
THE BOND MARKET AND FISCAL-MONETARY POLICY

\section{TABLE A.7. Correlation matrix with 9 shocks}

\begin{tabular}{c|ccccc}
\hline \hline Variables & $r_{s}-r$ & $r_{b}-r$ & $\pi$ & $\Delta c$ & $m$ \\
& $(\mathrm{M} / \mathrm{F})$ & $(\mathrm{M} / \mathrm{F})$ & $(\mathrm{M} / \mathrm{F})$ & $(\mathrm{M} / \mathrm{F})$ & $(\mathrm{M} / \mathrm{F})$ \\
\hline$r_{s}-r$ & 1.00 & $0.50 /-0.53$ & $-0.45 / 0.15$ & $0.52 / 0.57$ & $-0.66 /-0.38$ \\
$r_{b}-r$ & & 1.00 & $-0.48 /-0.14$ & $0.31 /-0.32$ & $-0.65 /-0.15$ \\
$\pi$ & & & 1.00 & $-0.72 / 0.04$ & $0.46 / 0.21$ \\
$\Delta c$ & & & & & $-0.34 /-0.25$ \\
$m$ & & & & & 1.00 \\
\hline \hline
\end{tabular}

Notes: This table reports the correlation matrix of financial and macroeconomic variables with all shocks in the model with 9 shocks. The variables include excess return on stock (claim on consumption) $\left(r_{s}-r\right)$, excess return on 5-year nominal bond $\left(r_{b}-r\right)$, inflation $(\pi)$, consumption growth $(\Delta c)$, and pricing kernel $(m)$. The numbers before and after the slash $(/)$ represent the correlations in the $\mathrm{M}$ regime and $\mathrm{F}$ regime, respectively. 


\section{FiguRE A.1. Impulse responses of a positive technology shock - ZLB}
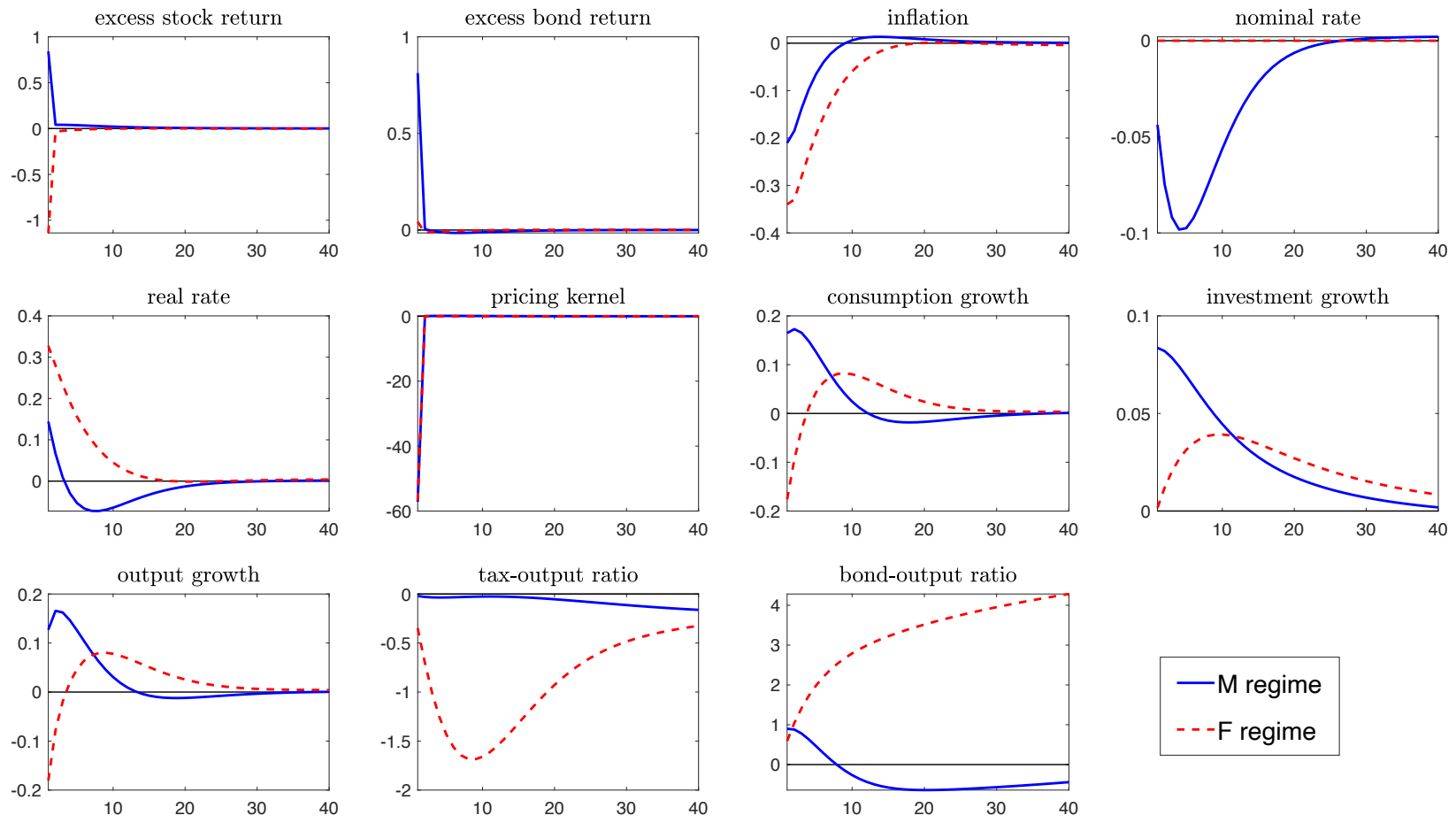

Notes: This figure plots the impulse responses of key macro and finance variables after a one-standarddeviation positive neutral technology shock, in the model with the F regime at the ZLB. The blue solid lines and red dashed lines represent impulse responses under the $\mathrm{M}$ and $\mathrm{F}$ regimes, respectively. The $\mathrm{x}$-axis shows the time in quarters, and the y-axis represents the percentage change from the steady state. 


\section{FigurE A.2. Impulse responses of a positive investment shock - ZLB}
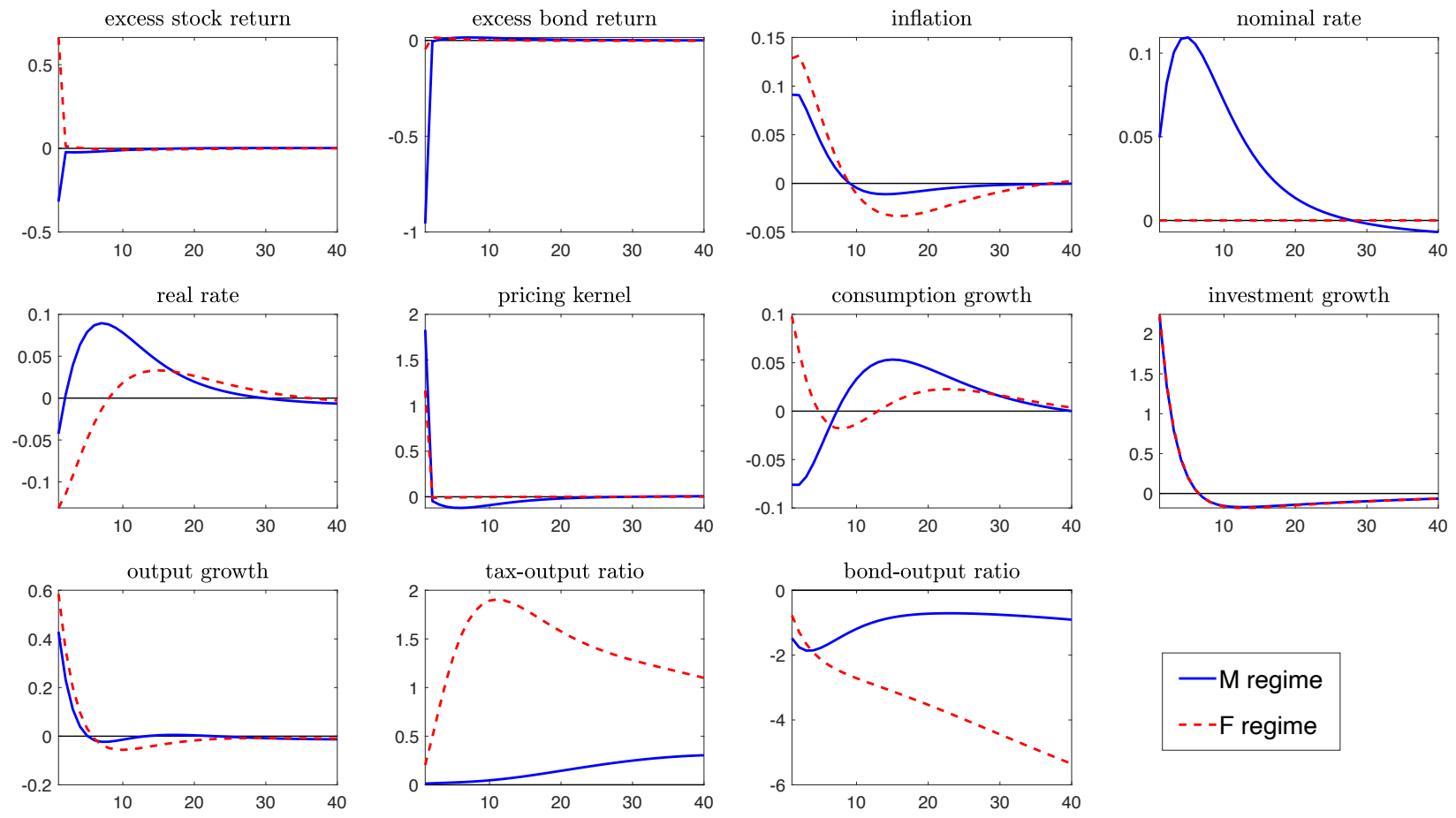

Notes: This figure plots the impulse responses of key macro and finance variables after a one-standarddeviation positive marginal efficiency of investment shock, in the model with the F regime at the ZLB. The blue solid lines and red dashed lines represent impulse responses under the $\mathrm{M}$ and $\mathrm{F}$ regimes, respectively. The $\mathrm{x}$-axis shows the time in quarters, and the $\mathrm{y}$-axis represents the percentage change from the steady state. 


\section{FIgURE A.3. Impulse responses of a positive techhology shock - CRRA preferences}
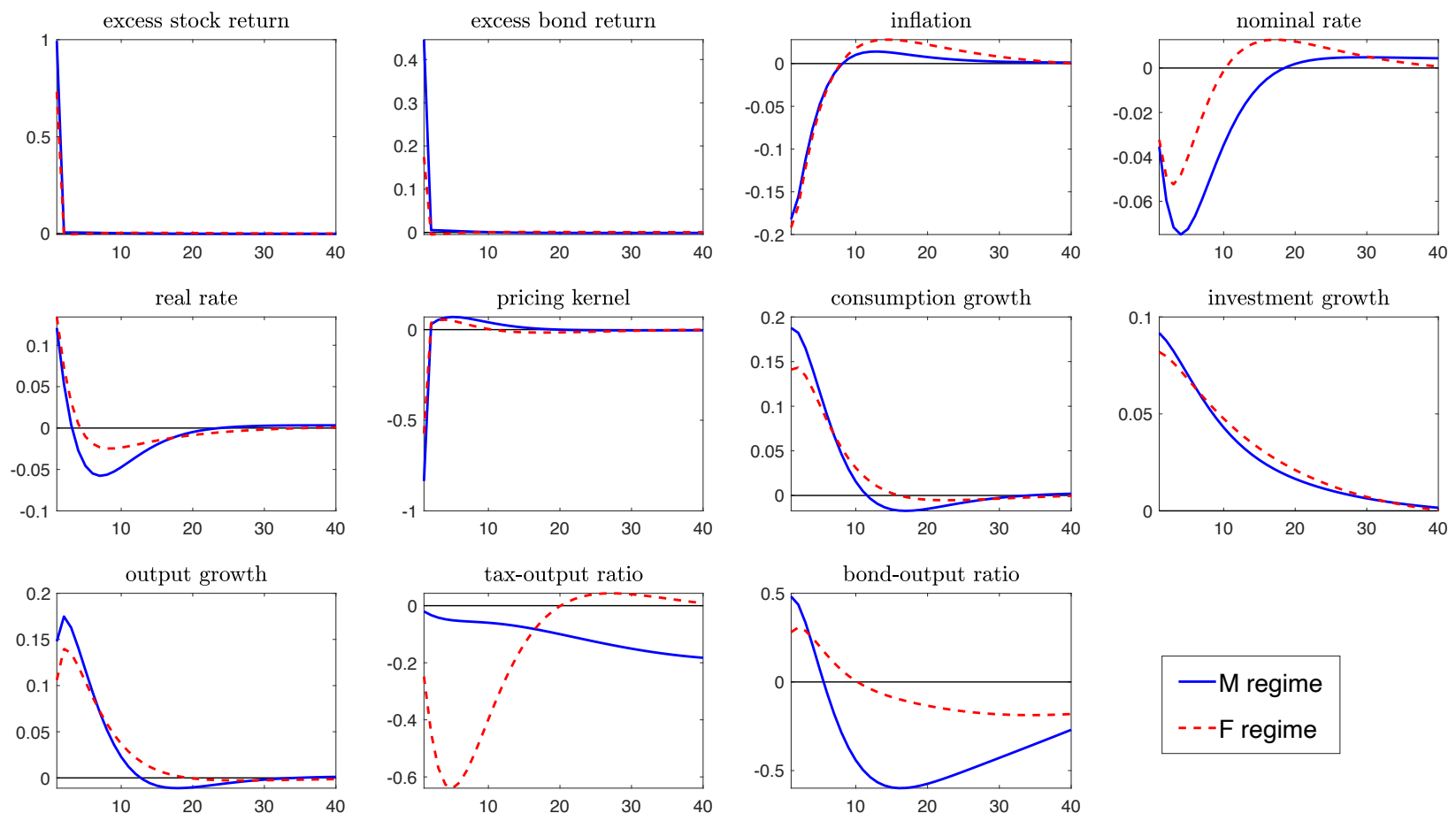

Notes: This figure plots the impulse responses of key macro and finance variables after a one-standarddeviation positive neutral technology shock, in the model with CRRA preferences. The blue solid lines and red dashed lines represent impulse responses under the $\mathrm{M}$ and $\mathrm{F}$ regimes, respectively. The $\mathrm{x}$-axis shows the time in quarters, and the y-axis represents the percentage change from the steady state. 


\section{FIGURE A.4. Impulse responses of a positive investment shock -} CRRA preferences
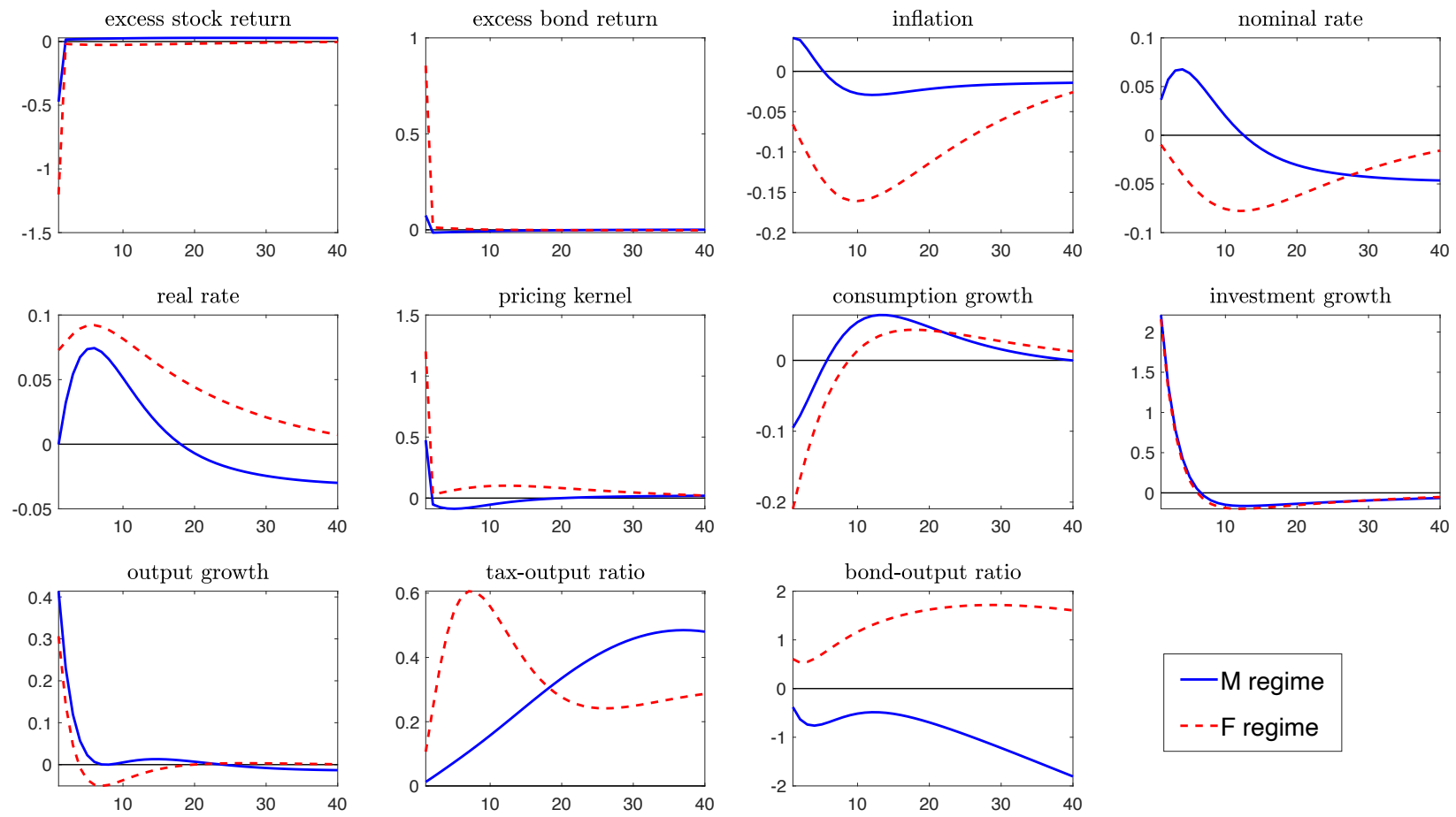

Notes: This figure plots the impulse responses of key macro and finance variables after a one-standarddeviation positive marginal efficiency of investment shock, in the model with CRRA preferences. The blue solid lines and red dashed lines represent impulse responses under the $\mathrm{M}$ and $\mathrm{F}$ regimes, respectively. The $\mathrm{x}$-axis shows the time in quarters, and the $\mathrm{y}$-axis represents the percentage change from the steady state. 


\section{FIgURE A.5. Impulse responses of a positive technology shock - without habit formation}
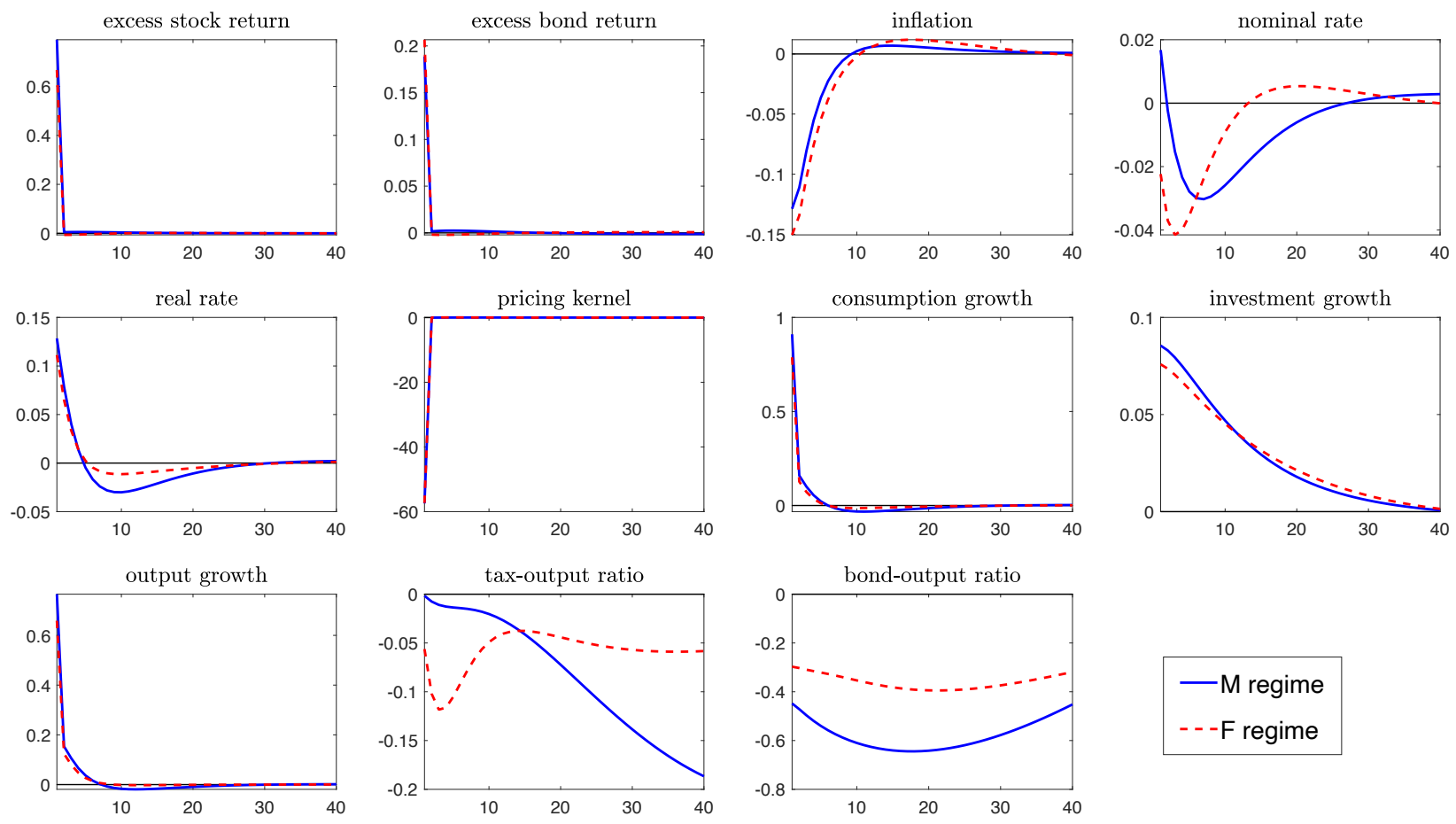

Notes: This figure plots the impulse responses of key macro and finance variables after a one-standarddeviation positive neutral technology shock, in the model without habit formation. The blue solid lines and red dashed lines represent impulse responses under the $\mathrm{M}$ and $\mathrm{F}$ regimes, respectively. The $\mathrm{x}$-axis shows the time in quarters, and the y-axis represents the percentage change from the steady state. 


\section{FIgURE A.6. Impulse responses of a positive investment shock - without habit formation}
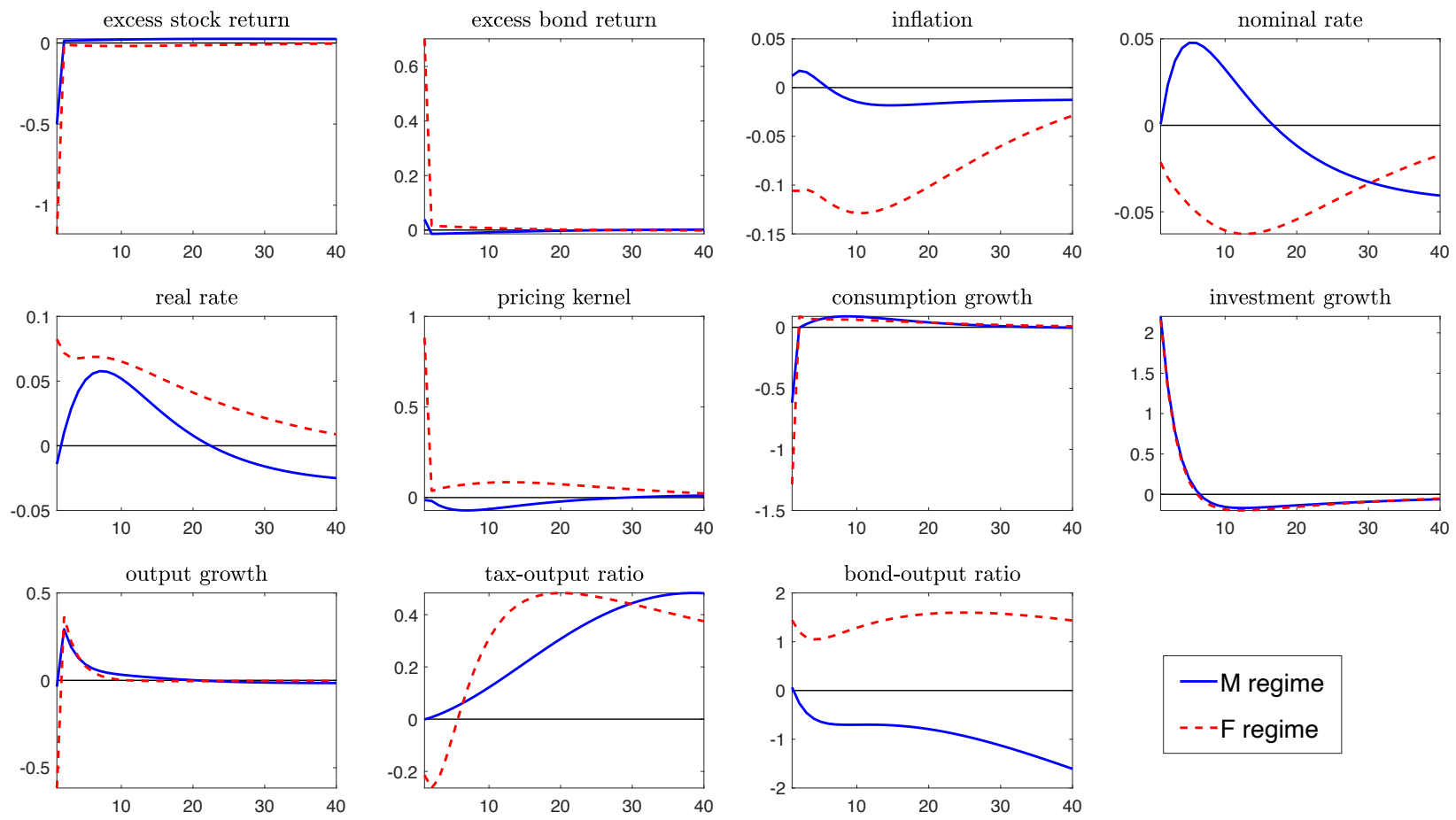

Notes: This figure plots the impulse responses of key macro and finance variables after a one-standarddeviation positive marginal efficiency of investment shock, in the model without habit formation. The blue solid lines and red dashed lines represent impulse responses under the $\mathrm{M}$ and $\mathrm{F}$ regimes, respectively. The $\mathrm{x}$-axis shows the time in quarters, and the $\mathrm{y}$-axis represents the percentage change from the steady state. steady state. 


\section{FiguRE A.7. Impulse responses of a positive technology shock}
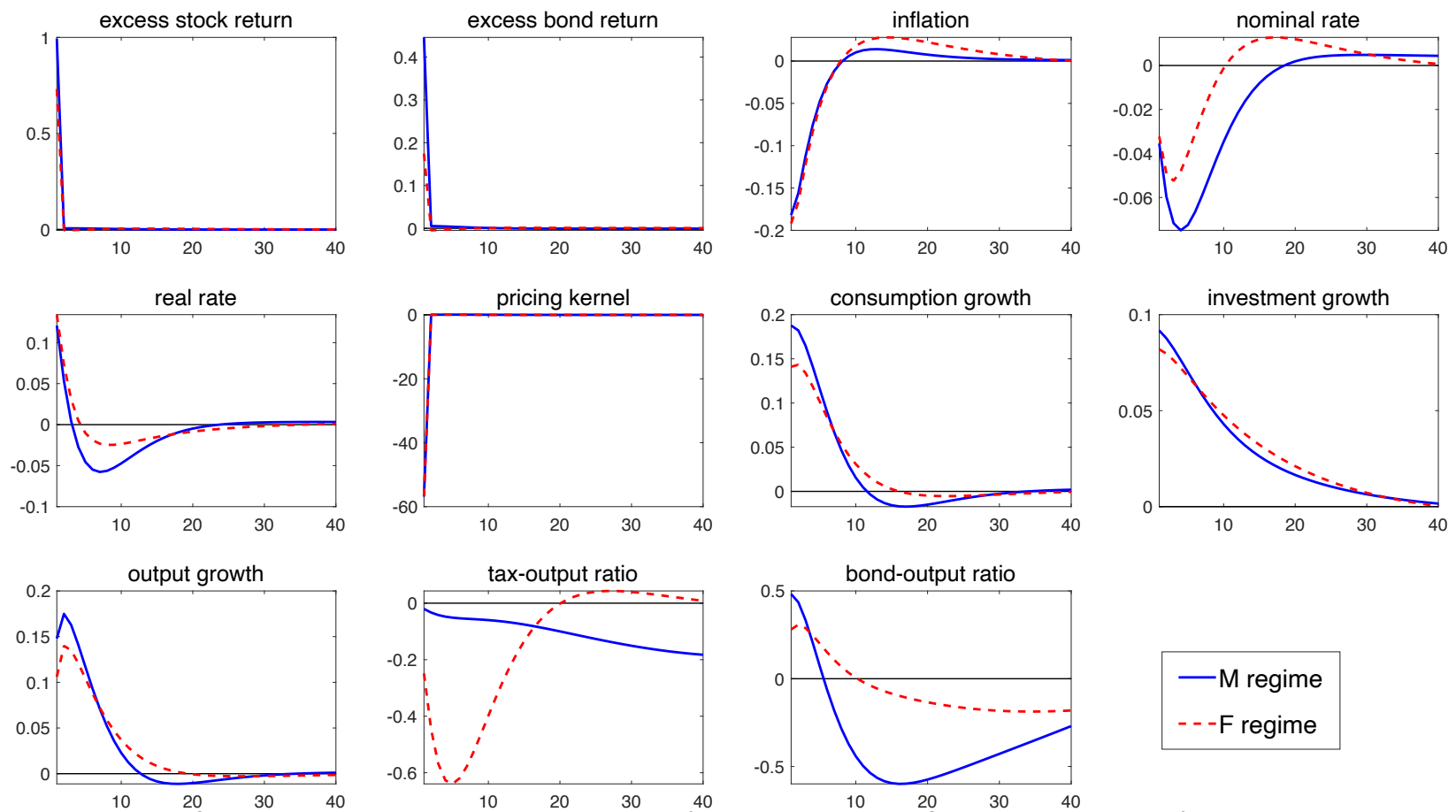

Notes: This figure plots the impulse responses of key macro and finance variables after a one-standarddeviation positive technology shock in the baseline model. The blue solid lines and red dashed lines represent impulse responses under the $\mathrm{M}$ and $\mathrm{F}$ regimes, respectively. The $\mathrm{x}$-axis shows the time in quarters, and the $\mathrm{y}$-axis represents the percentage change from the steady state. 
FIGURE A.8. Impulse responses of a positive investment shock
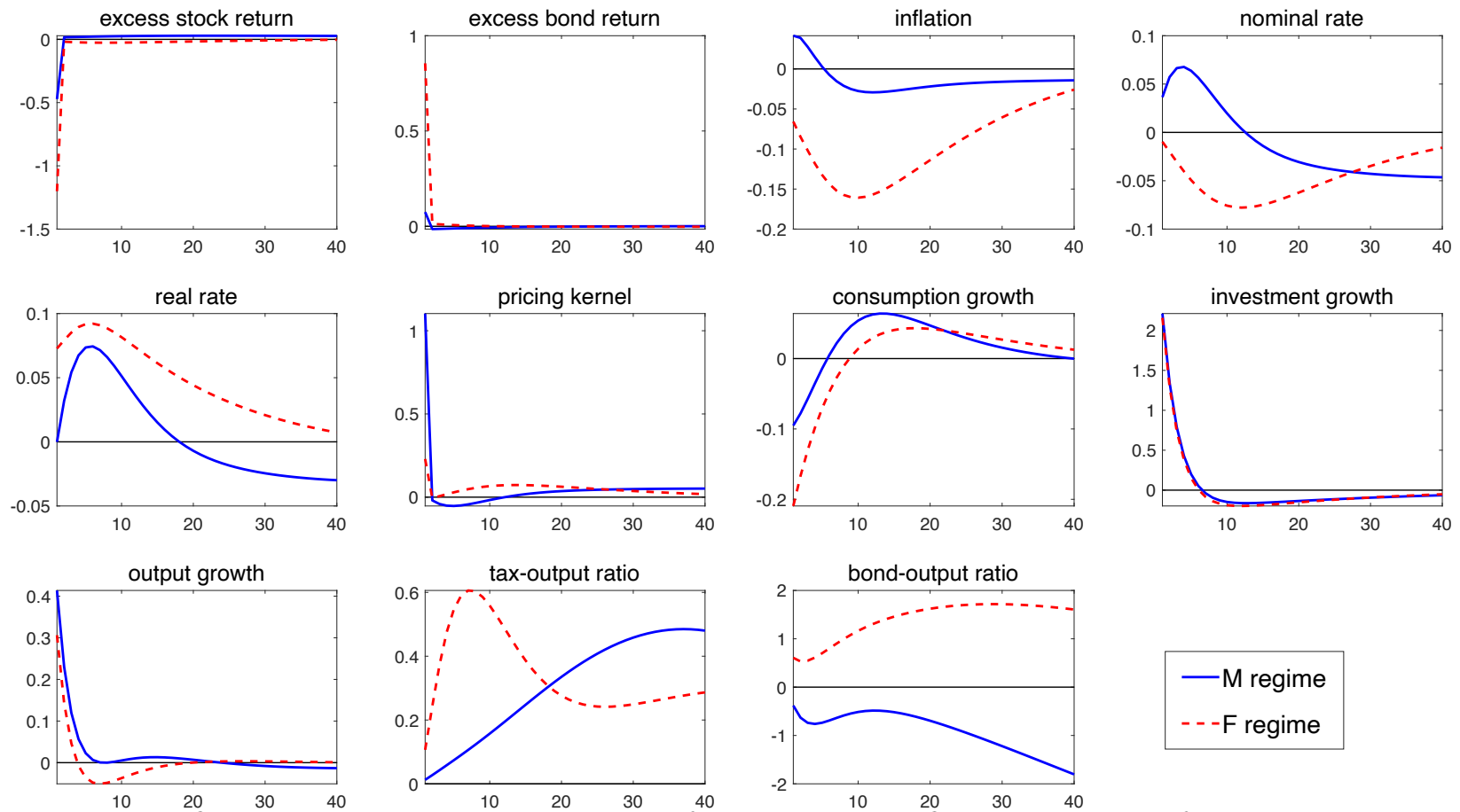

Notes: This figure plots the impulse responses of key macro and finance variables after a one-standarddeviation positive investment shock in the baseline model. The blue solid lines and red dashed lines represent impulse responses under the $\mathrm{M}$ and $\mathrm{F}$ regimes, respectively. The $\mathrm{x}$-axis shows the time in quarters, and the $\mathrm{y}$-axis represents the percentage change from the steady state. 


\section{FIGURE A.9. Impulse responses of a positive monetary policy shock}
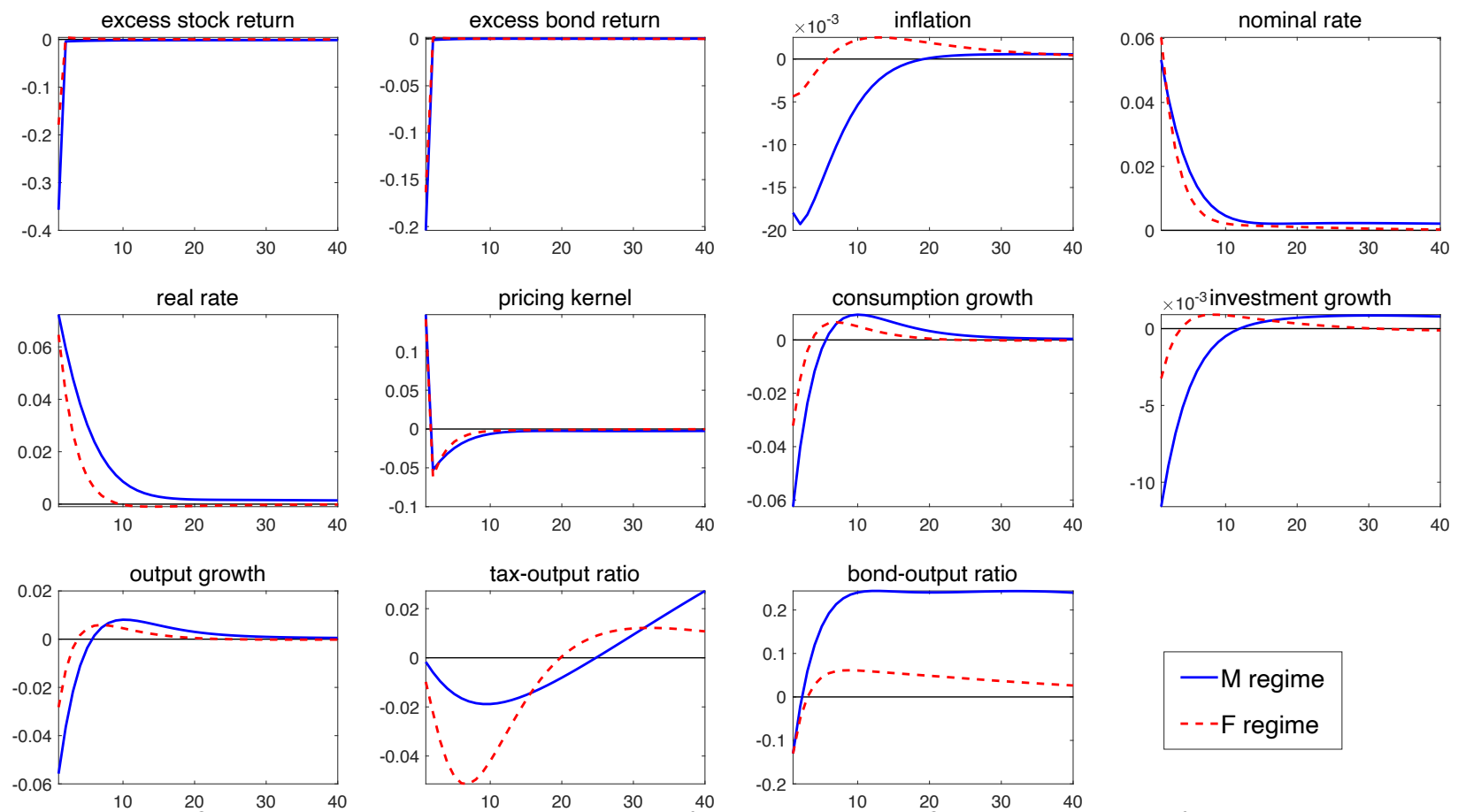

Notes: This figure plots the impulse responses of key macro and finance variables after a one-standarddeviation positive monetary policy shock in the baseline model. The blue solid lines and red dashed lines represent impulse responses under the $\mathrm{M}$ and $\mathrm{F}$ regimes, respectively. The $\mathrm{x}$-axis shows the time in quarters, and the $\mathrm{y}$-axis represents the percentage change from the steady state. 
FIgURE A.10. Impulse responses of a positive fiscal policy shock
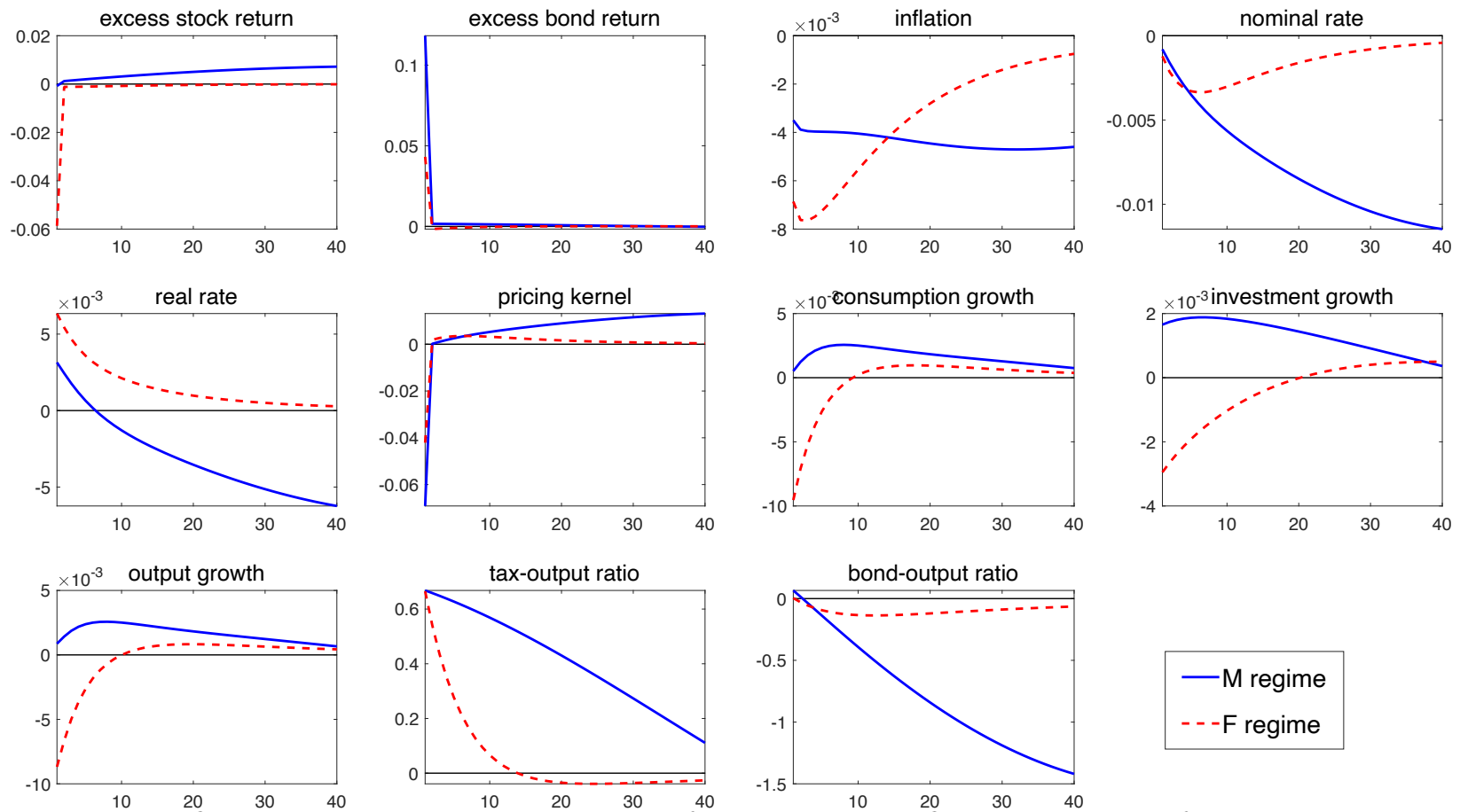

Notes: This figure plots the impulse responses of key macro and finance variables after a one-standarddeviation positive fiscal policy shock in the baseline model. The blue solid lines and red dashed lines represent impulse responses under the $\mathrm{M}$ and $\mathrm{F}$ regimes, respectively. The $\mathrm{x}$-axis shows the time in quarters, and the $\mathrm{y}$-axis represents the percentage change from the steady state. 
FiguRE A.11. Impulse responses of a positive total factor productivity (TP) shock
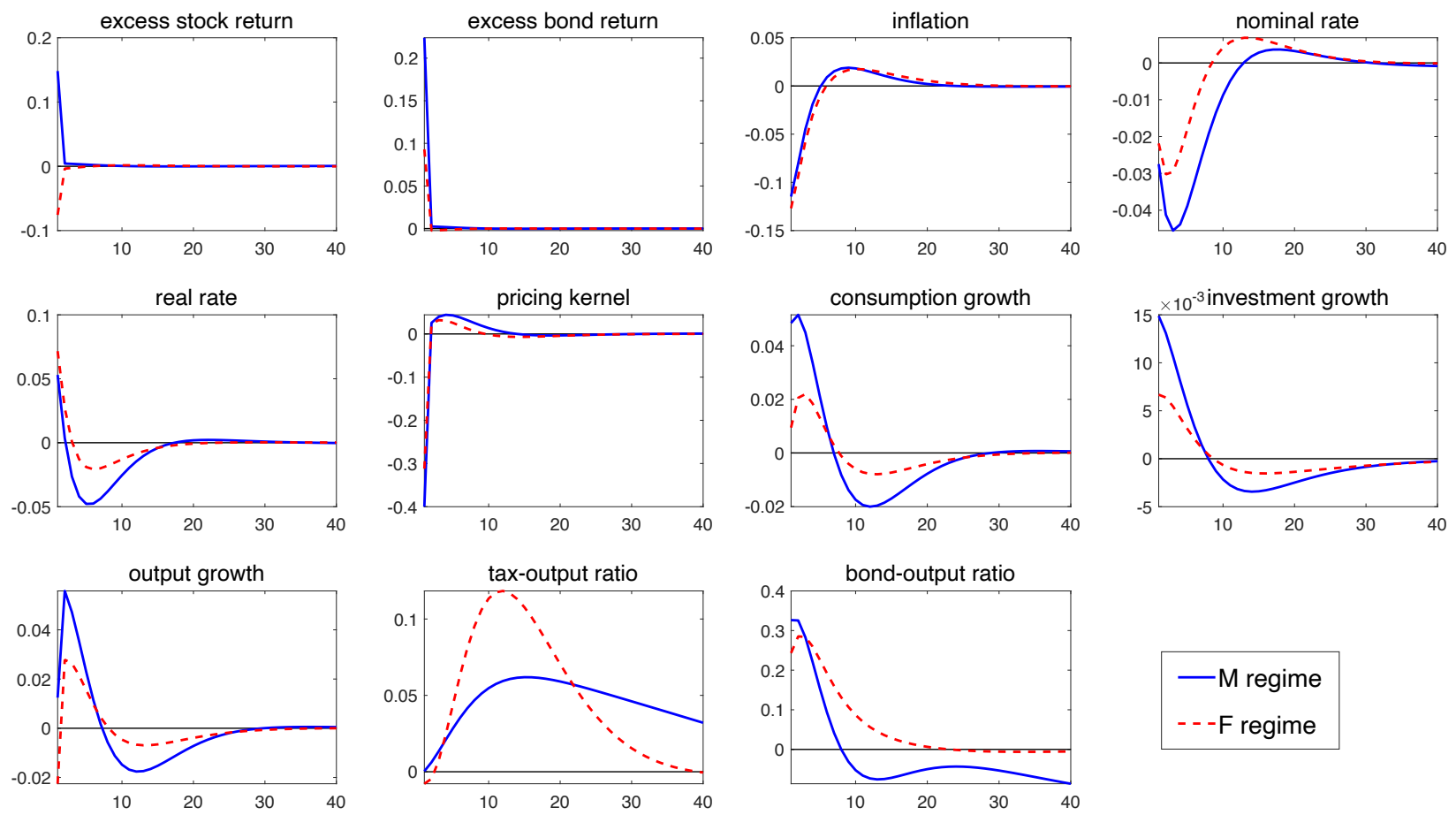

Notes: This figure plots the impulse responses of key macro and finance variables after a one-standarddeviation positive total factor productivity shock in the extended model. The blue solid lines and red dashed lines represent impulse responses under the $\mathrm{M}$ and $\mathrm{F}$ regimes, respectively. The $\mathrm{x}$-axis shows the time in quarters, and the $\mathrm{y}$-axis represents the percentage change from the steady state. 


\section{FIgURE A.12. Impulse responses of a positive investment-specific technology (IST) shock}
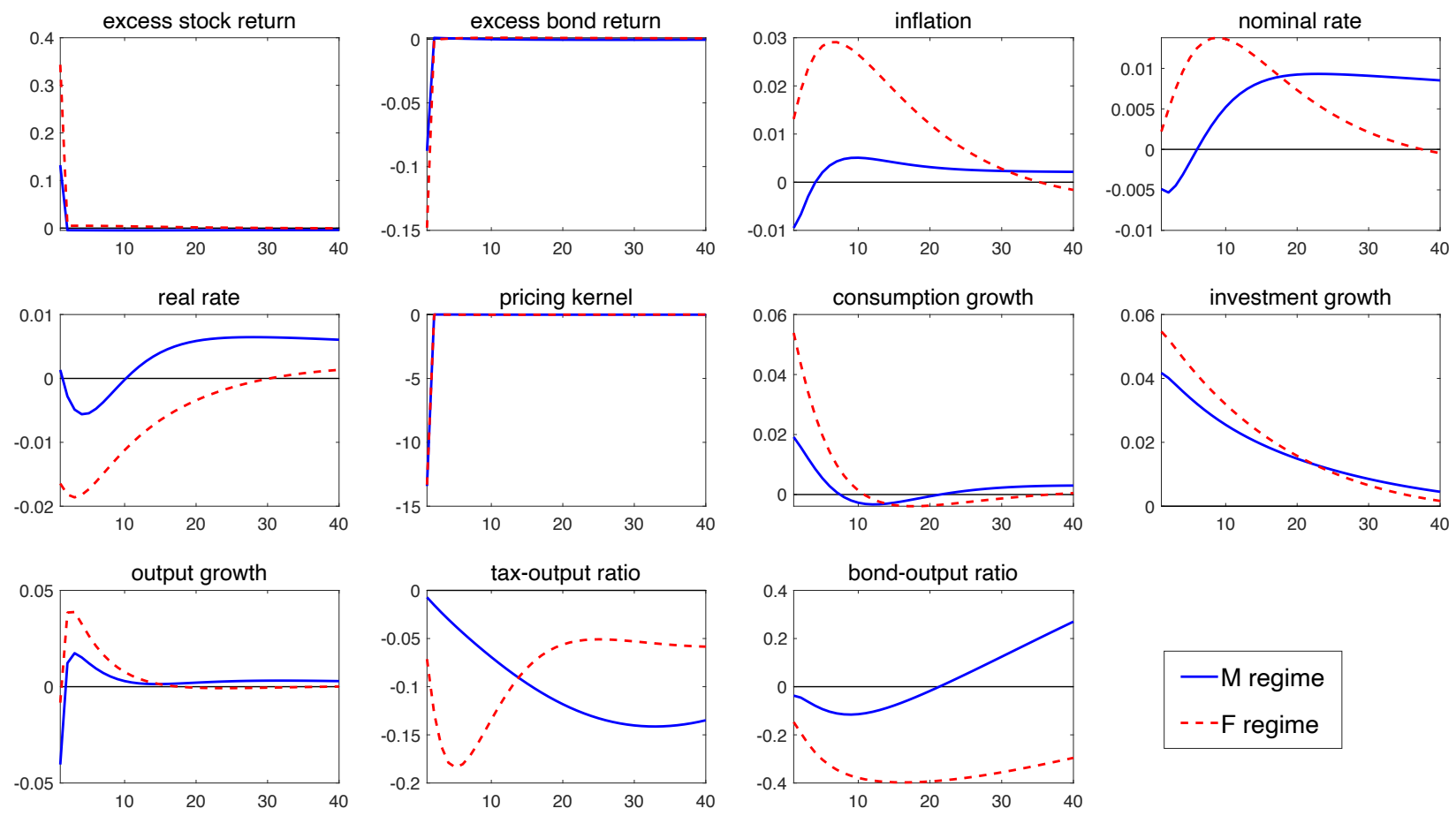

Notes: This figure plots the impulse responses of key macro and finance variables after a one-standarddeviation positive investment-specific technology shock in the extended model. The blue solid lines and red dashed lines represent impulse responses under the $\mathrm{M}$ and $\mathrm{F}$ regimes, respectively. The $\mathrm{x}$-axis shows the time in quarters, and the $y$-axis represents the percentage change from the steady state. 


\section{Figure A.13. Impulse responses of a positive price markup (PM) shock}
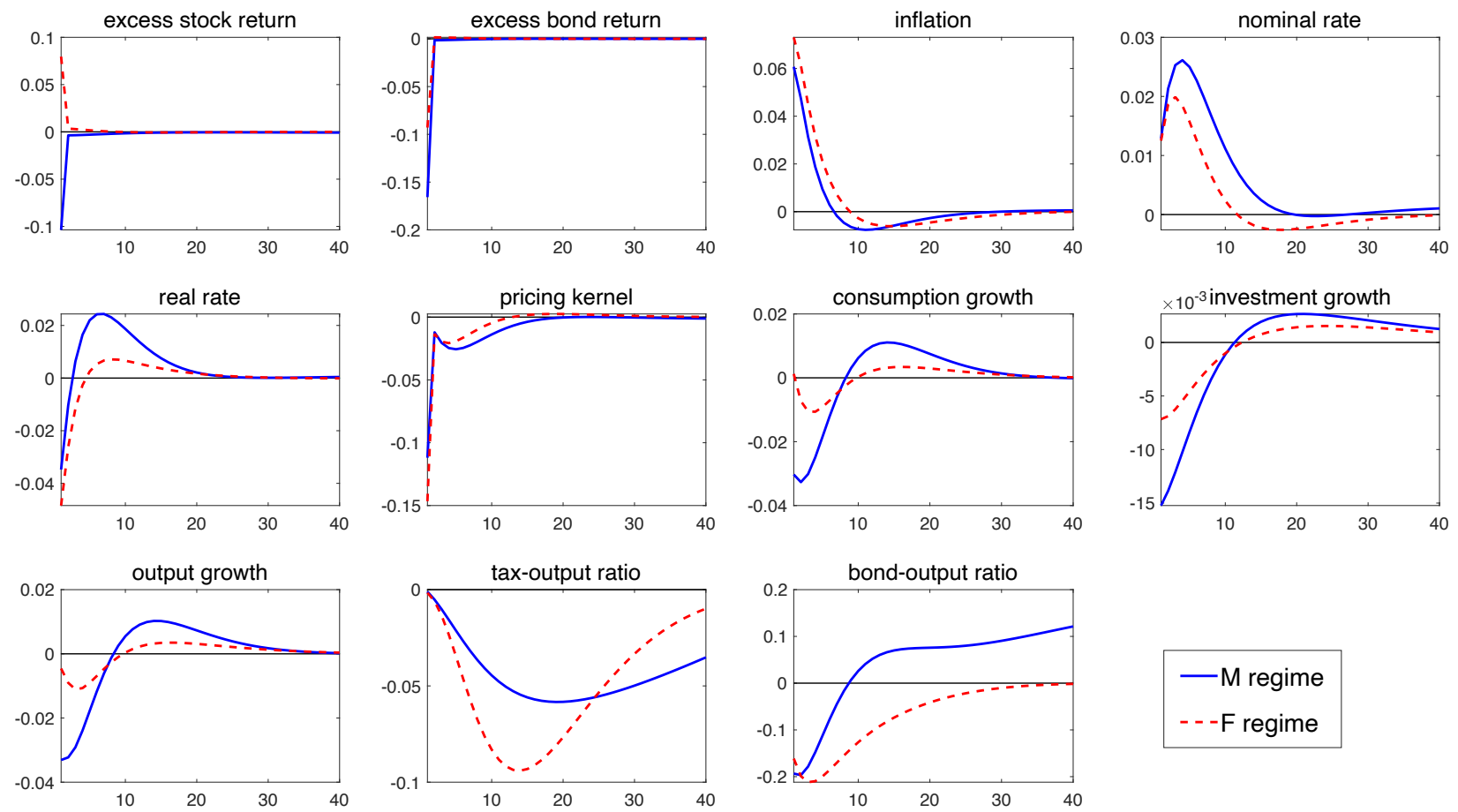

Notes: This figure plots the impulse responses of key macro and finance variables after a one-standarddeviation positive price stickiness shock in the extended model. The blue solid lines and red dashed lines represent impulse responses under the $\mathrm{M}$ and $\mathrm{F}$ regimes, respectively. The $\mathrm{x}$-axis shows the time in quarters, and the $y$-axis represents the percentage change from the steady state. 


\section{FigurE A.14. Impulse responses of a positive wage markup (WM) shock}
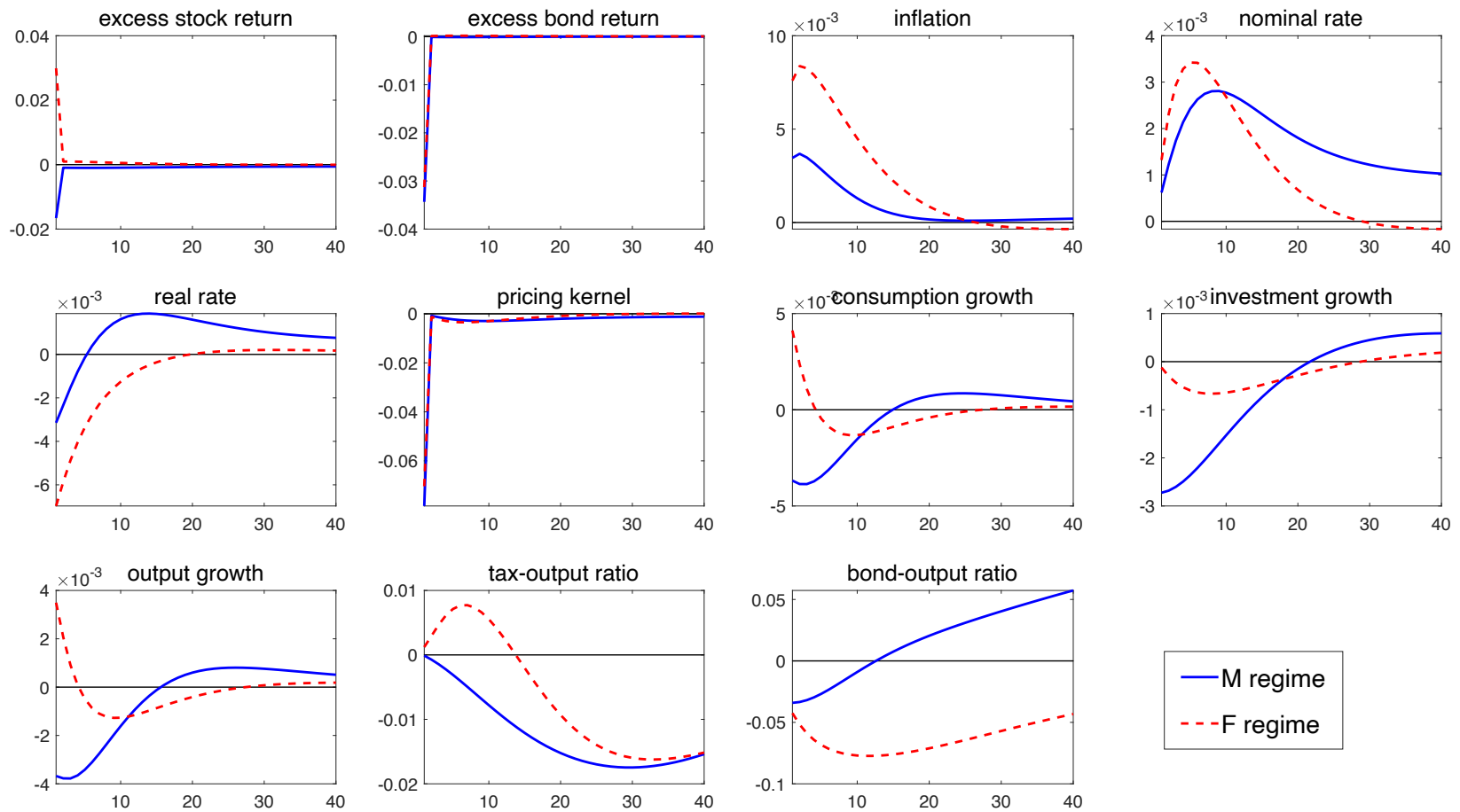

Notes: This figure plots the impulse responses of key macro and finance variables after a one-standarddeviation positive wage stickiness shock in the extended model. The blue solid lines and red dashed lines represent impulse responses under the $\mathrm{M}$ and $\mathrm{F}$ regimes, respectively. The $\mathrm{x}$-axis shows the time in quarters, and the $\mathrm{y}$-axis represents the percentage change from the steady state. 


\section{FiguRE A.15. Impulse responses of a positive labor supply (LS) shock}
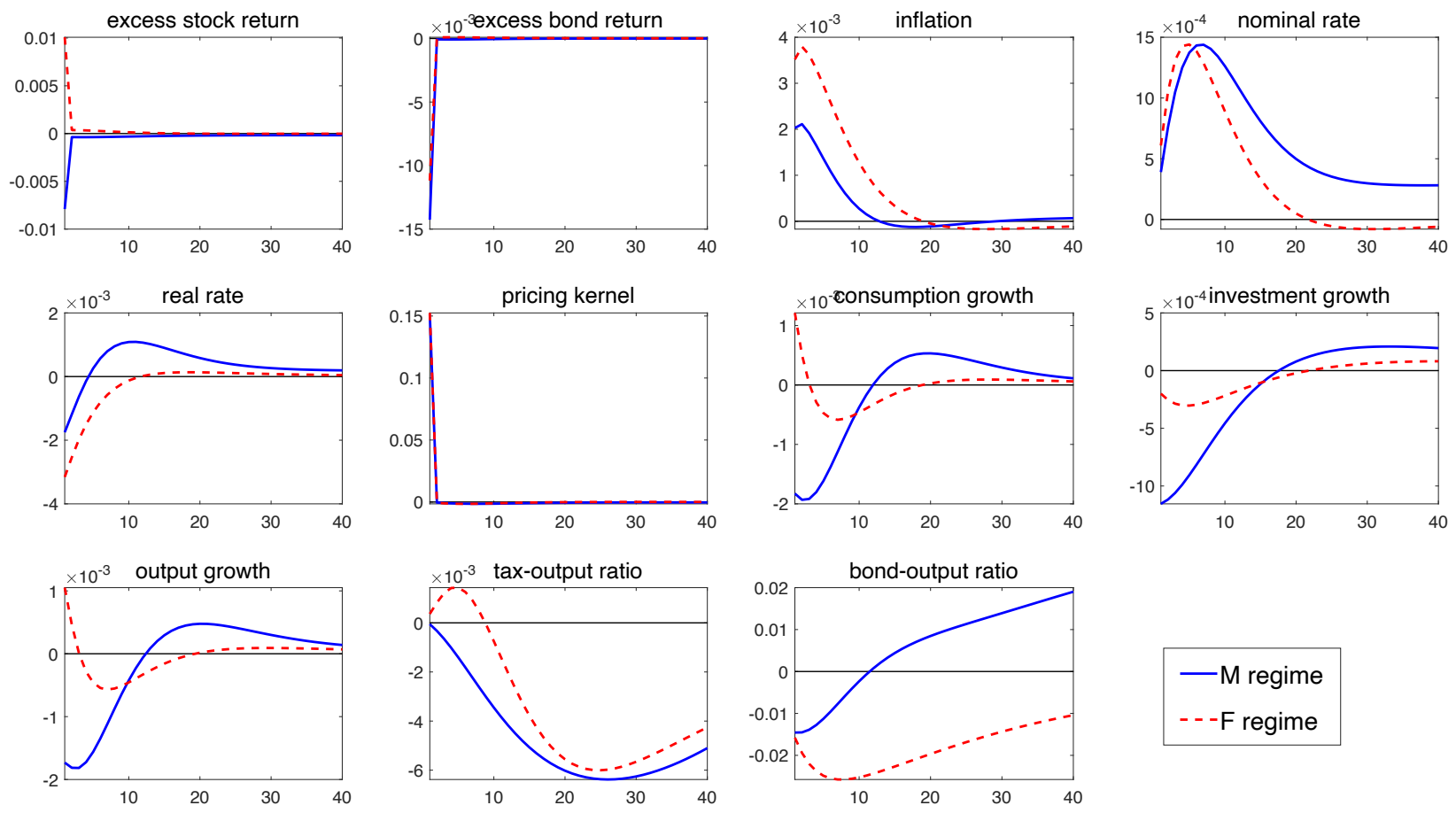

Notes: This figure plots the impulse responses of key macro and finance variables after a one-standarddeviation positive labor supply shock in the extended model. The blue solid lines and red dashed lines represent impulse responses under the $\mathrm{M}$ and $\mathrm{F}$ regimes, respectively. The $\mathrm{x}$-axis shows the time in quarters, and the $\mathrm{y}$-axis represents the percentage change from the steady state. 